النطاق المادى

للقانون الدولى الإنسانى

$$
\text { إعداد }
$$

د. سيف غانم السويدى

استاذ القانوز الدولى العام المشارك

$$
\text { شرطة دبـى }
$$

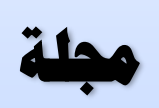

جنوب الوادي

للدراسات القانونية

\section{العدد الثالث}

$\mathbf{r} \cdot \mathbf{1 1}$ 


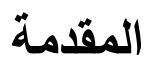

باعتبار أن القانون الدولي الإنساني هو قانون خاص بالنزاعات المسلحة، فإن تطبيقه يتوقف على وجود حالة نزاع مسلح. وبما أن القانون الدولي الإنساني يميز بين أنواع النزاعات المسلحة - فمنها ما يكيفها على أنها نزاعات مسلحة دولية وأخرى يعتبرها داخلية وغيرها ينظر إليها باعتبارها مجرد أعمال عنف عرضية أو اضطرابات وتوترات داخلية لا ترقى لوصف نزاع مسلح داخلي - فإنه من الضروري البحث في النطاق المادي للقانون الدولي الإنساني والذي من خلاله سيتم تحديد ماهية النزاعات المسلحة

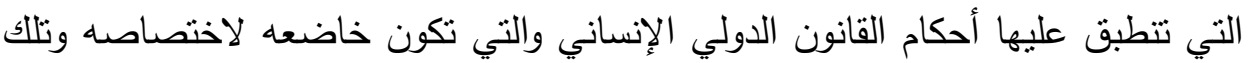
التي تستبعد من ذلك الاختصاص، أي التي تظل خاضعة لسلطان القانون الداخلي.

وسيتضح من البحث في هذا الجزء بأن المنازعات المسلحة الخاضعة لاختصاص

القانون الدولي الإنساني ـ ـوفقاً لنصوص اتفاقيات جنيف الأربع وبروتوكوليها الإضافيين

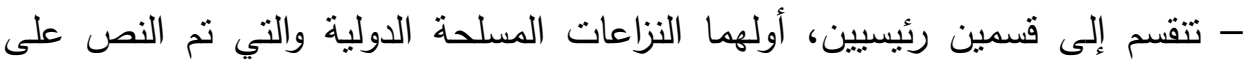

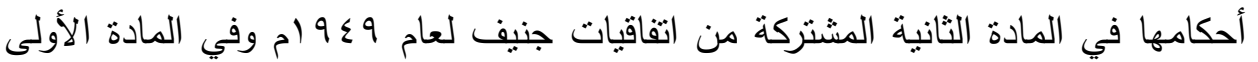
من البروتوكول الإضافي الأول لعام 9VV ام ، وثانيهما النزاعات المسلحة غير الدولية (الداخلية) والتي وردت أحكامها في المادة الثالثة المشتركة من اتفاقيات جنيف الأربع لعام المات

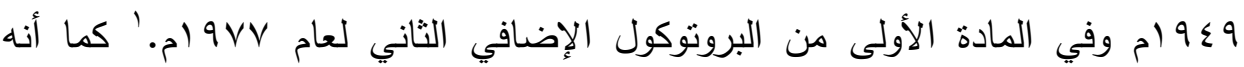

' تجدر الإشارة إلى أن الفقه التقليدي، وفي إطار الدفهوم التقليدي للحرب، كان يميز بين ثلاثة أنواع من

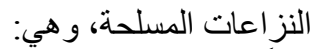

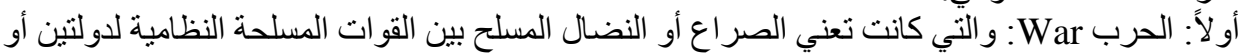

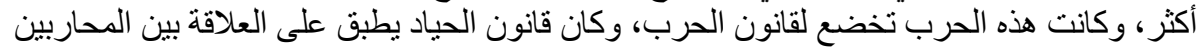

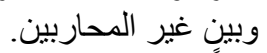

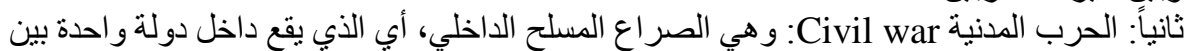

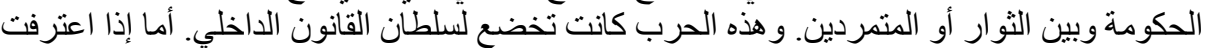

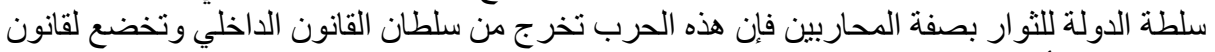

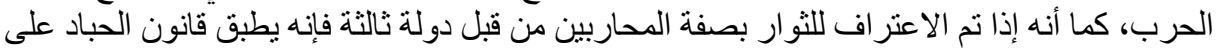

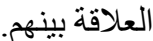

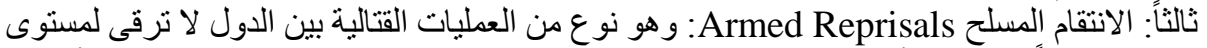

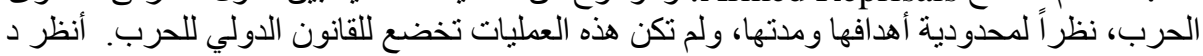

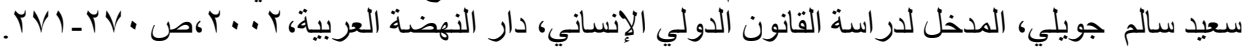

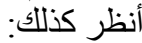


سيتبين بأن هناك نوع آخر من النزاعات المسلحة - يضاف من قبل الفقه غير منصوص

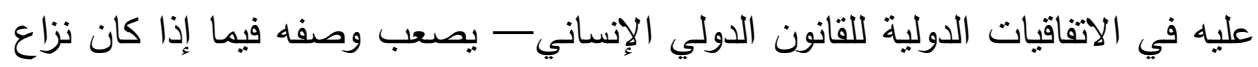
دولي أم داخلي وذلك بسبب تداخل بعض العناصر والمعطيات، وهو ما يعرف بالنزاعات المسلحة المدولة.

لذا، فإن التركيز في هذا البحث سينصب على تحديد مضمون هذه النزاعات والذي من خلاله سيتم تحديد النطاق المادي للقانون الدولي الإنساني وإلى تمييز النزاعات

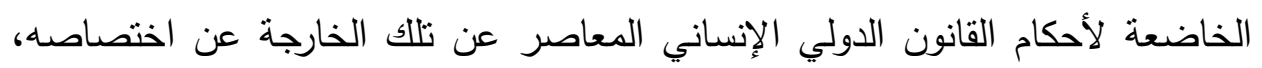
حيث سيتم التعرض بالتقصيل للنزاعات والأوضاع التالية: أولاً:- النزاعات المسلحة الدولية والتي تضم (أ) الحرب المعلنة أو أب اشتباك

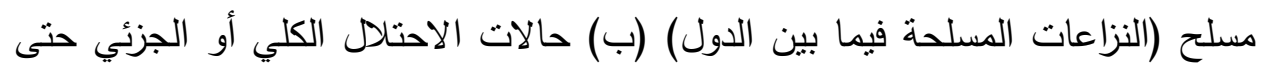

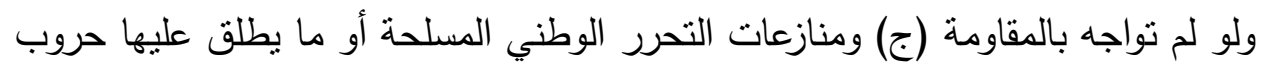
التحرير الوطنية، ولو باهُ

ثانياً:- النزاعات المسلحة غير الدولية أو المعروفة باسم النزاعات المسلحة الداخلية، وهي إما أن تكون عامة معرفة تعريف سلبي وفقاً لما ورد في المادة الثالثة

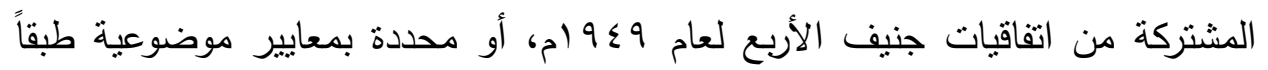

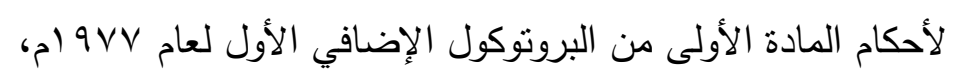
ثالثاً :- النزاعات المسلحة المدولة التي لم تتم الإثارة إليها في اتفاقيات القانون الدولي الإنساني ولكن الواقع العملي والفقه كثف عن وجودها المؤكد، رابعاً :- كما أن هذا البحث سبتطرق لبعض الحالات التي يستخدم فيها العنف ولكن لا يشملها القانون الدولي الإنساني كالاضطرابات والتوترات الداخلية. وقبل الخوض في تفاصيل هذه التقسيمات للنزاعات المسلحة، فإنه من الضروري

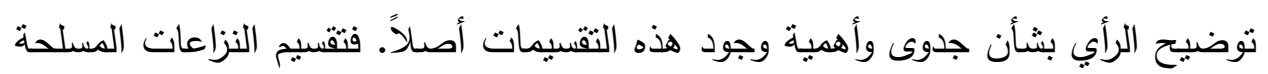


د د سيف غازم السويدى

إلى دولية أو غير دولية يؤدي إلى ترتيب أثز قانوني خطير بتمثل في اختلاف القواعد

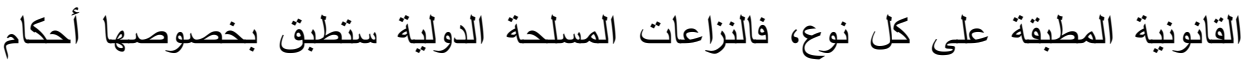
القانون الدولي الإنساني الخاصة بالنزاعات المسلحة الدولية فقط (فثناً ستطبق بشأنها

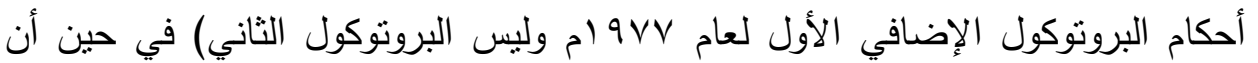
النزاعات المسحلة الداخلية (غير الدولية) فإنها ستخضع لأحكام القانون الدولي الإنساني

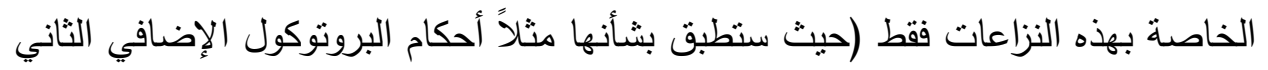
لعام 9VV ام وليس البروتوكول الأول). وذللك يعتبر غير منوافق مع الغرض الإنساني للقانون الدولي الإنساني، حيث يفترض تطبيق مجمل مضمون وقواعد القانون الدولي الإنساني على جميع صور النزاعات المسلحة وبصرف النظر عن أب معيار شكلي آخر يتخذ كأساس للتمييز فيما بينها. وفي الحقيقة، فإن هذه التفرقة، علاوة على أنها تبطل الغرض الإنساني للقانون الدولي الإنساني الذي يهدف إلى حماية ضحايا النزاعات

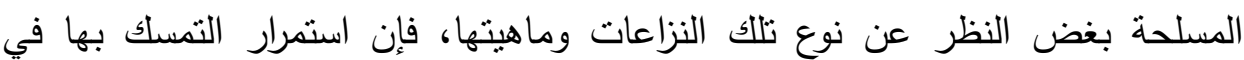
الوقت المعاصر اصبح أمراً غير مقبولاً خاصة بعدما أوضحت اللجنة الدولية للصليب

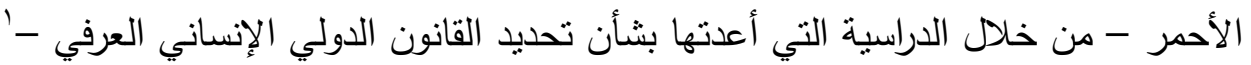
بأن قواعد القانون الدولي الإنساني هي قواعد عرفية معظمها قابل للتطبيق على كلا

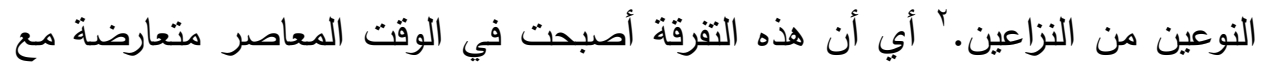
شمولية قواعد القانون الدولي الإنساني المكتسبة للصفة العرفية.

' ل لمزيد من التفاصيل بشأنها أنظر جون ماري هنكرتس و لويز دوزو الد بك، القانون الدولي الإنساني

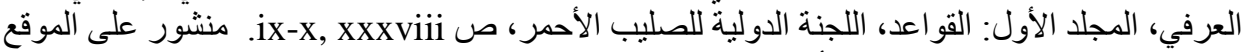

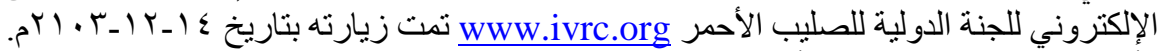

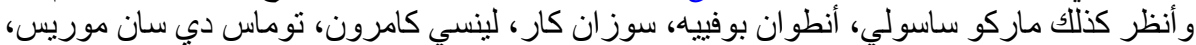

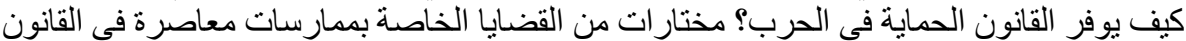
الدولي الإنساني، اللجنة الدولَية للصليب الأحمر، الطبعة الأولى، المركز الإقليمي للإعلام، القاهرة،

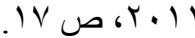

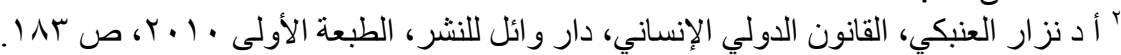




\section{المبحث الأول}

\section{النزاعات المسلحة الدولية}

جاء النص على أحكام ومضدون النزاعات المسلحة الدولية في المادة الثانية

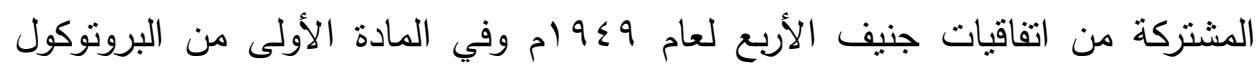

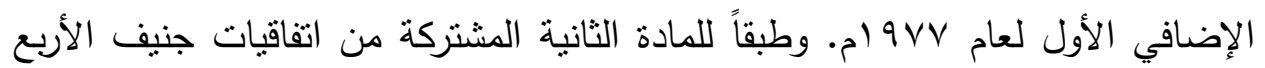

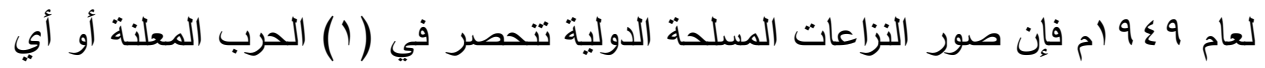

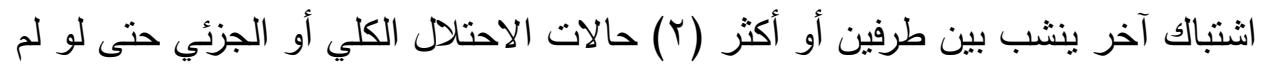
يواجه بمقاومة مسلحة. في حين أضافت المادة الأولى من البروتوكول الإضافي الأول لعام $9 V V$ ام "حروب التحرير الوطنية" كصورة من صور النزاعات المسلحة الدولية. وعليه، فإنه سيتم تقسيم هذا المبحث إلى مطلبين، يتتاول الأول صور النزاعات المسلحة

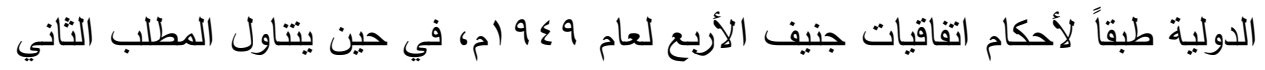

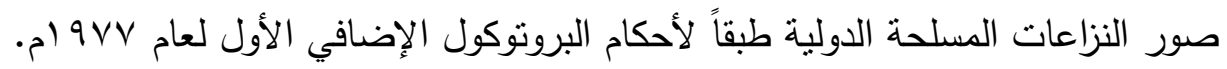


د/ /سيف غائم السويدى

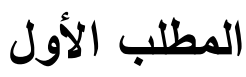

\section{النزاعات المسلحة الدولية طبقاً لأحكام اتفاقيات جنيف الأريع لعام}

\section{p) $9 \& 9$}

تتص المادة الثانية المشتركة من اتفاقيات جنيف الأربع لعام 9 \ ام على أنه: "علاوة على الأحكام التي تسري في وقت السلم، تتطبق هذه الاتفاقية في حالة

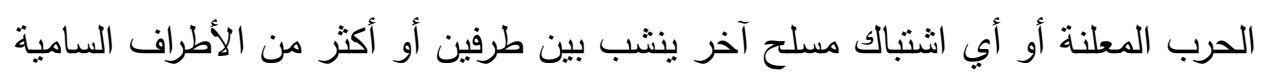
المتعاقدة، حتى لو لم بعترف أحدها بحالة الحرب.

كما تتطبق الاتفاقية أيضاً في جميع حالات الاحتلال الجزئي أو الكلي لإقليم أحد الأطراف السامية المتعاقدة، حتى لو لم يواجه هذا الاحتلال مقاومة مسلحة. وإذا لم تكن إحدى دول النزاع طرفاً في هذه الاتفاقية، فإن دول النزاع الأطراف فيها

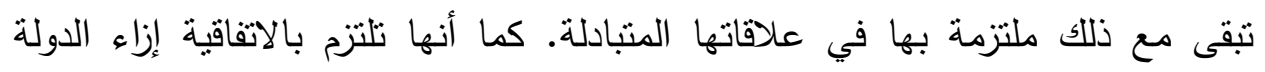

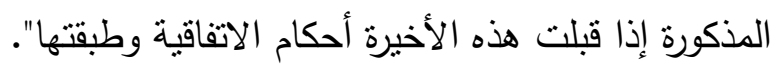

فالصورة الأولى من صور النزاعات المسلحة الدولية المشار إليها في الفقرة الأولى

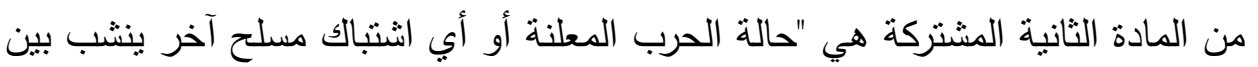
طرفين أو أكثر من الأطراف السامية المتعاقدة، حتى لو لم يعترف احدها بحالة الحرب".

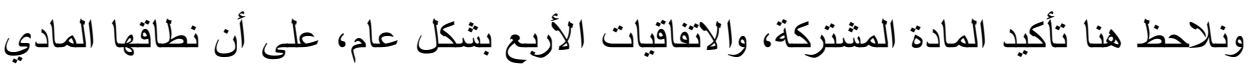

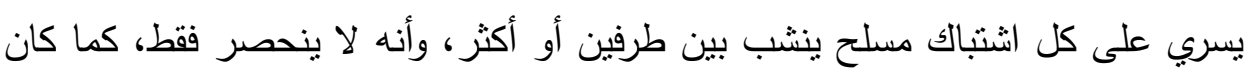

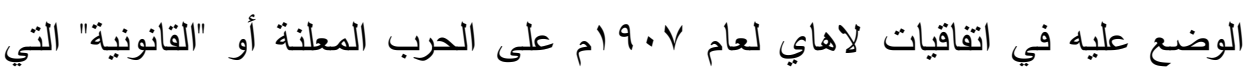

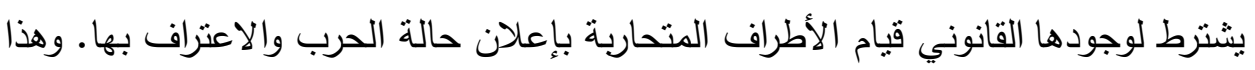

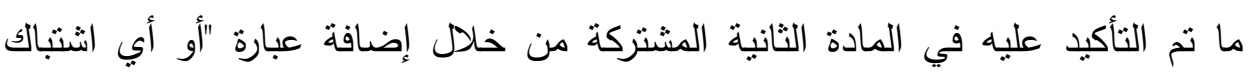

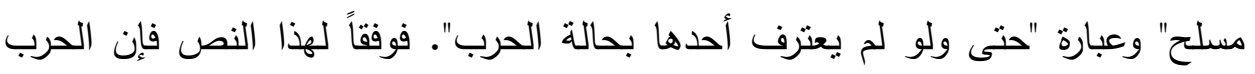
القانوينة تعتبر صورة واحدة، وليست الوحيدة، من صور النزاعات المسلحة الدولية في الوقت المعاصر • وهذا ما أكده كذللك القضاء الدولي، على سبيل المثال، في حكم 


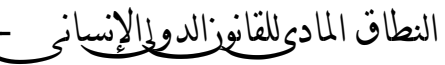

المحكمة الخاصة بيوغوسلافيا السابقة في قضية Tadic بأنه "وبكل بساطة يوجد نزاع

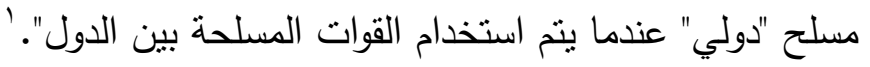

وعليه، فإن الاتفاقيات تطبق في وقتتا المعاصر بمجرد اندلاع العمليات الحربية

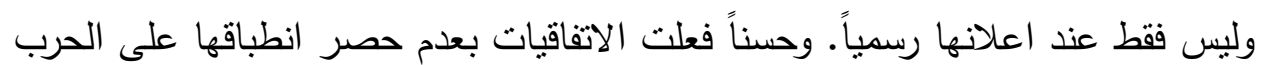
القانونية التي تحتاج لإقرار وجودها من الناحية القانونية اتخاذ إجراء الإعلان من قبل التانل أطرافها والاعتراف بوقوعها، لأنه لو استمر الوضع على ذلك لكان بامكان أطراف هذه التهان الحرب استبعاد تطبيق أحكام القانون الدولي الإنساني على حربهم بمجرد عدم اعترافهم أو أو الوان

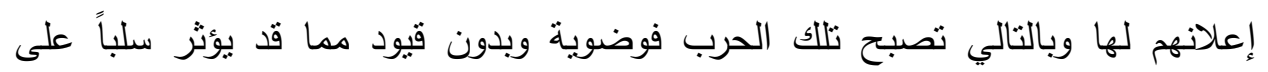

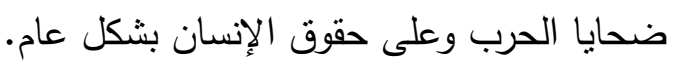

أما الصورة الثانية من صور النزاعات الدسلحة الدولية الدشار إليها في الفقرة الثانية

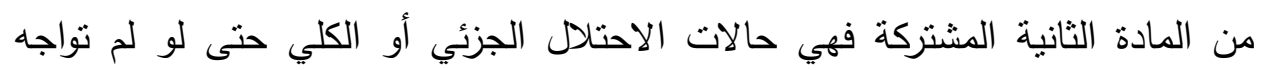

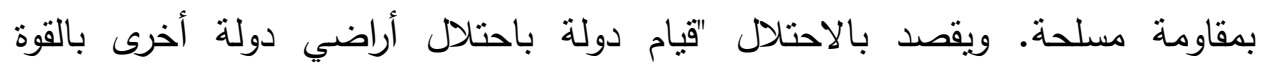

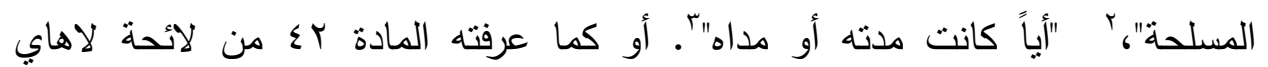

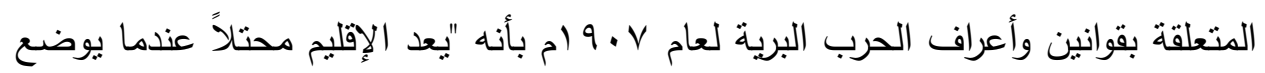

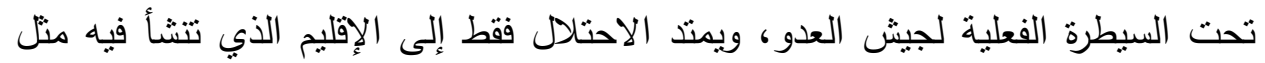

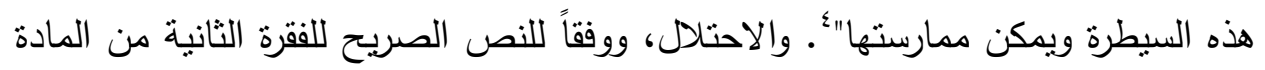
الثانية المشتركة من اتفاقيات جنيف، يعتبر قائماً سواء كان كلياً أو جزئياً وسواء تدت

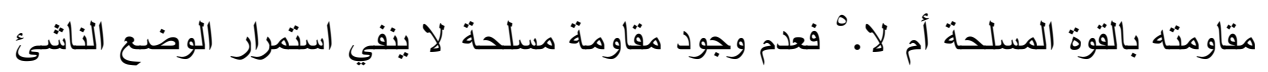

' The prosecutor v. Tadic (Appeal on jurisdiction) 2Oct. 1995, case no : . 1T.94-1-AR72 (Appeal chamber, ICTY) at 37 Para. 70.

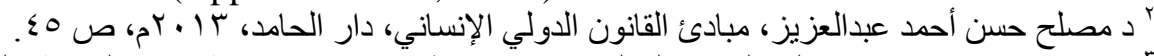

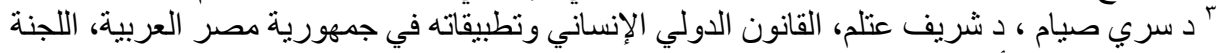

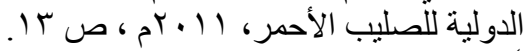

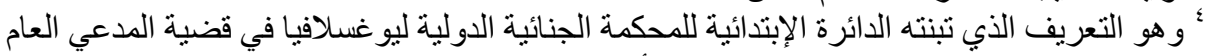

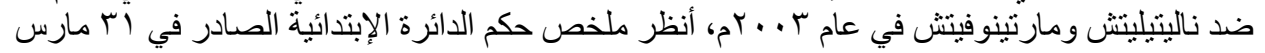

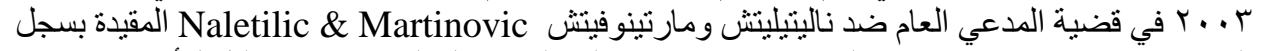

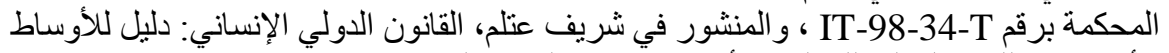

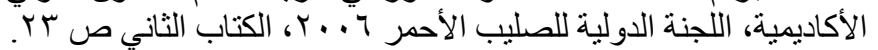
Jonathan Crowe \& Kylie Weston-Scheuber, op.cit., p. 10.

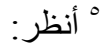


د د سيف غازم السويدى

عن الاحتلال باعنباره نزاع مسلح بين الدولة المحتلة ودولة الاحتلال، وبالتالي تخضع

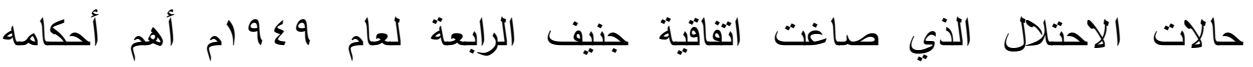
لاختصاص ونطاق القانون الدولي الإنساني. فهو في جميع الأحوال بعتبر نوع من الاعن النزاعات المسلحة الدولية الخاضع لأحكام القانون الدولي الإنساني. 


\section{المطلب الثاني}

\section{النزاعات المسلحة الدولية}

\section{طبقاً لأحكام البروتوكول الإضافي الأول لعام 9 VV}

أكدت الفقرة الثالثة من المادة الأولى من البروتوكول الإضافي الأول لعام 9VV

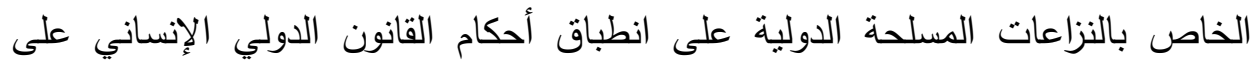

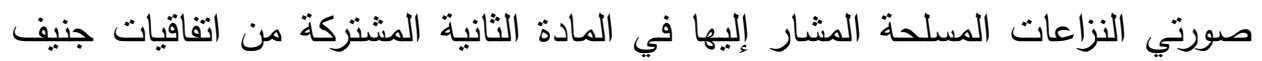
الأربع لعام 9 \ ام، وأضاف في الفقرة الرابعة من ذات المادة من البروتوكول صورة ثالثة

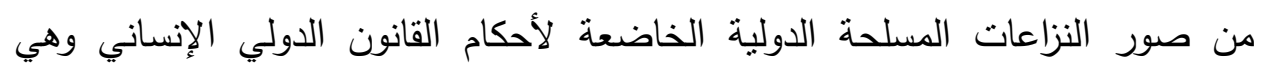
"حروب التحرير الوطنية"، والتي تم تعريفها على أنها " المنازعات المسلحة التي تتاضل لإنل

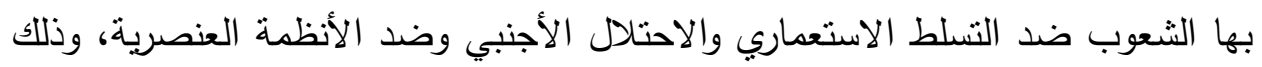
في ممارستها لحق الثعوب في ثقرير المصير، كما كرسه ميثاق الأمم المتحدة والإعلان المتعلق بمبادئ القانون الدولي الخاصة بالعلاقات الودية والتعاون بين الدول طبقاً لميثاق

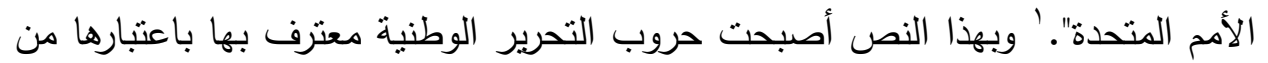

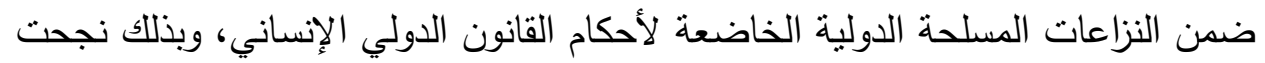

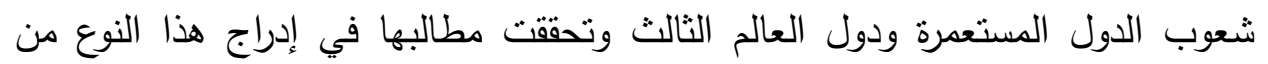
النزاعات ضمن النزاعات المسلحة الدولية بالرغم من صعوبة المناقثات والمفاوضات التي أحاطت بهذا البند في أثناء المؤتمر الدبلوماسي لتأكيد وتطوير القانون الدولي الإنساني الذي انعقد في جنيف عام 9 ام وقبل أن تسفر المناقثات عن تبني البروتوكولين الإضافيين لعام $9 V V$

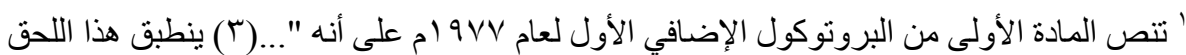

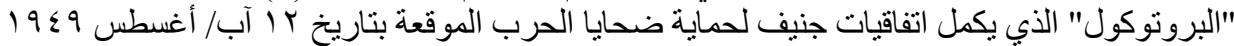

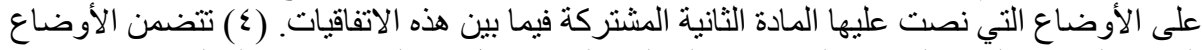

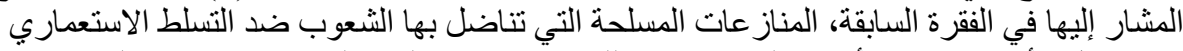

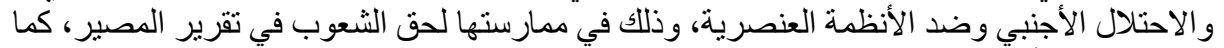

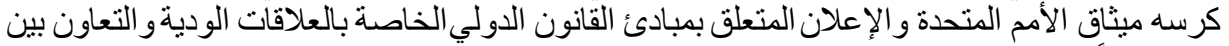
الدول طبقاً لميثاق الأمم المتحدة. 
والسؤال الذي يثور هو ما هي الحكمة من إضافة البروتوكول الإضافي الأول لعام 9 VV

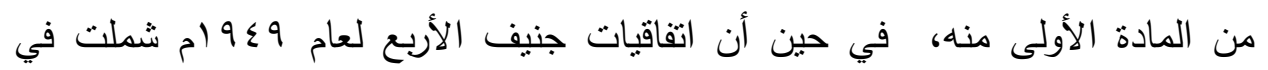

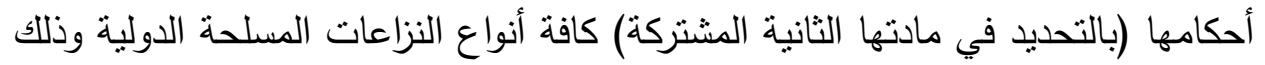
باستخدام عبارة "أو أي اثتباك آخر ينشب بين طرفين أو أكثر" ، "وحالات الاحتلال الجزئي أو الكلي". في الحقيقة، يتمثل القصد في الرغبة على نأكيد إبعاد حروب التحرير الوطنية من نطاق المنازعات المسلحة غير الدولية والتي كانت تحكمها (ققط) المادة الثالثة المشتركة من اتفاقيات جنيف الأربع لعام 9 \ ام وإدخالها ضمن نطاق المنات المنازعات

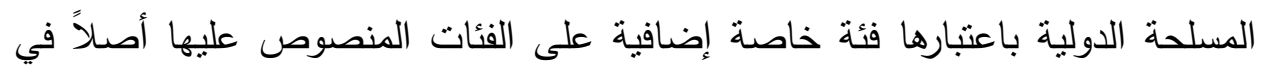

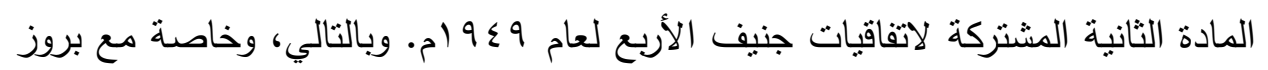

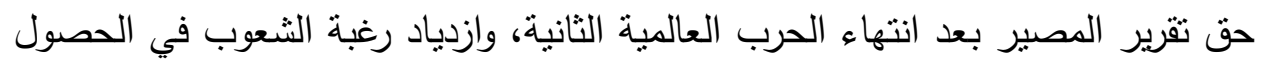

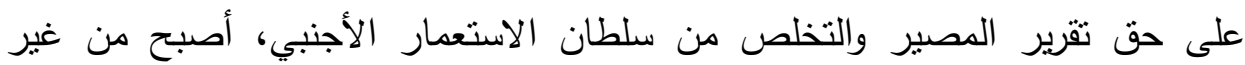
الجائز قانوناً لسلطات دول الاحتلال أن تدعي بعدم نوافر حق لتلاك الثعوب في النضال

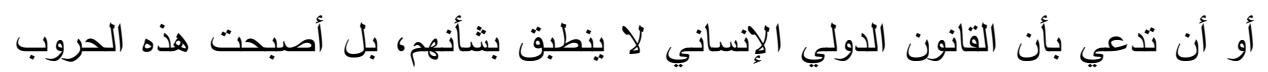

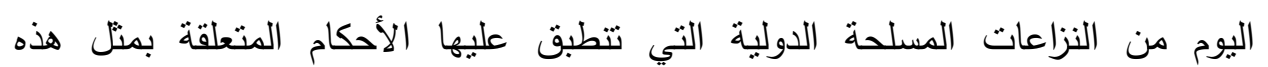
المنازعات وبالتالي مؤهلة للانتفاع من الحماية المطبقة في النزاعات المسلحة الدولية. وهذا ما ينطبق بالضبط بالنسبة لحرب التحرير الفلسطينية ضد الاحتلال الإسرائيلي الغاشم.

فحروب التحرير الوطنية تمارسها حركات التحرير الوطنية باعتبارها سلطة ممنلة

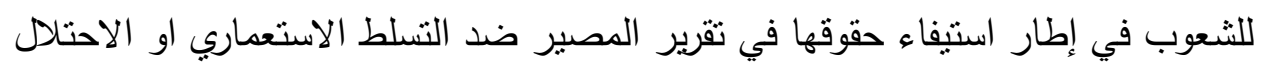
الأجنبي وضد الأنظمة العنصرية. وكي تدخل أحكام الاتفاقيات والبروتوكول الإضافي الأول لعام 9VV ام حيز التطبيق بالنسبة للسلطة بوصفها طرفاً في النزاع، وحتى يصبح من المكن تطبيق القواعد التي تحكم المنازعات المسلحة الدولية على منازعات التحرر بالئه الوطنية المسلحة وبالتالي تتمتع تلك السلطة بكافة الحقوق وتتحمل كافة الالتزامات التي تلتي تتعلق بأي طرف متعاقد لآخر ، فإنه ووفقاً لما نصت عليه الفقرة الثالثة من المادة بـ 9 من 
البروتوكول الإضافي الأول'، يجب على هذه السلطة أن تتعهد بتطبيق الاتفاقيات

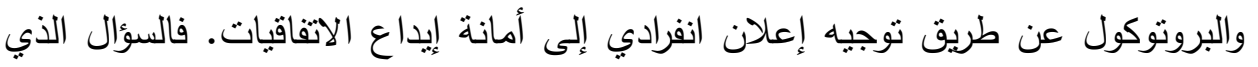

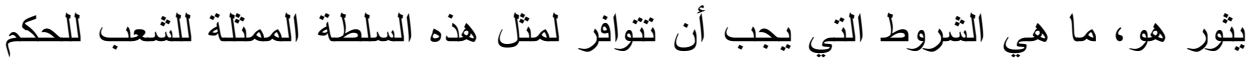
بأن لها الأهلية القانونية لإصدار ذلك الإعلان؟ يضع الفقه عدة شروط، أهمها، الثرط الأول: - أن تكون السلطة ممثلة للشعب

وهي تكون كنلك منى ما حصلت السلطة خلال اندلاع النزاع المسلح وقيادتها له على دعم وإِناد النشب، وتعتبر طول مدة النزاع وقيام السلطة بواجباتها باعتبارها سلطة ممثلة للشعب دليل وافي على توافر هذا الثرط التمثيلي. ولكن هذا الدعم والإسناد قد تعتريه بعض الإنكاليات والصعوبات في تحديده ومن ثم في تحديد مدى اعتبار السلطة

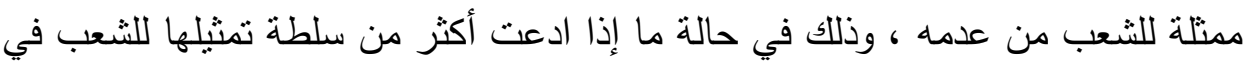

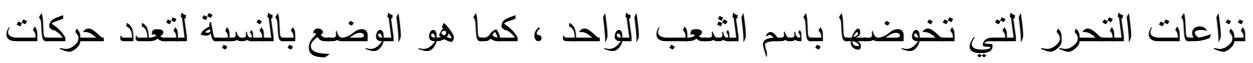

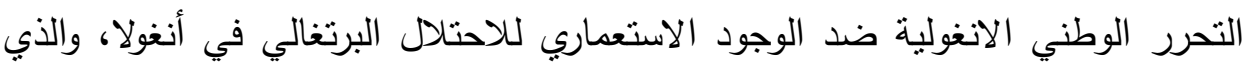

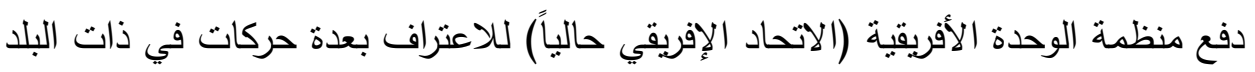

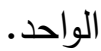

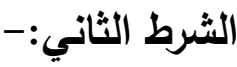

أن تنوافر لحركة التحرر الوطنية خصائص القوة المسلحة (الموضحة تفاصيلها في

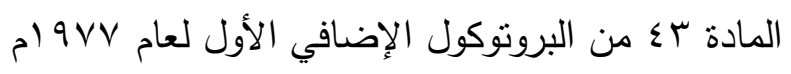

' تتص الفقرة الثالثة من المادة بو على أنه: "يجوز للسلطة الممثلة لشعب مشتبك مع طرف سام متعاقد

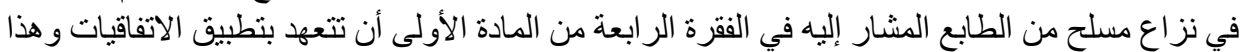

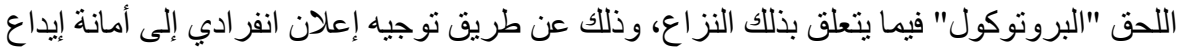

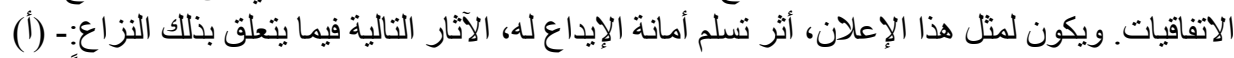

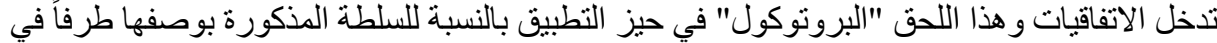

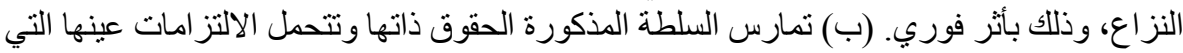

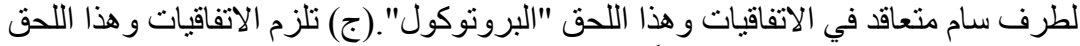

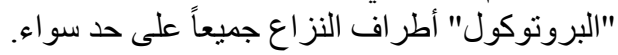

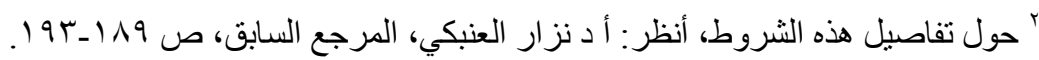


د د سيف غانم السويدى

طبقاً لهذا الثرط فإنه يجب أن تكون حركة التحرر الوطنية منظمة كقوة مسلحة لها قيادة مسؤولة عن مرؤوسيها، وأن تكون مزودة بنظام انضباط داخلي تخضع لله عملياتها

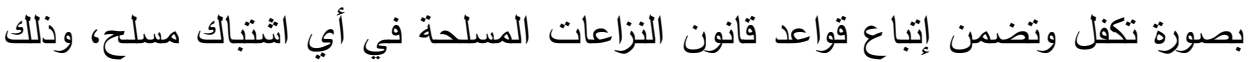
لكي تتمكن من الوفاء بتبعات التعهد بتطبيق اتفاقيات جنيف والبروتوكول. وتقدير توافر هذه الخصائص ومدى ممارسة قيادة حركة التحرر الوطني للقدر الملائم من التظظيم والرقابة والسيطرة على مقاتليها يعتبر من الأمور التقديرية التي يصعب ضبط ضبطها موضوعياً. ولكن، يمكن القول بأن من أهم المؤشرات الدالة على نقص التنظيم والرقابة والسيطرة هو ازدياد انتهاك قواعد قانون النزاعات المسلحة من قبل مقاتلي الحركة، وعجز

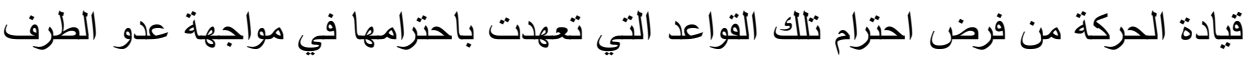

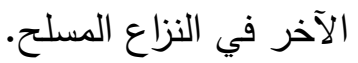

\section{الثرط الثالث:- اعتراف المنظمات الإقليمية الحكومية بالحركة}

استتاداً لوجود ممارسات عملية دولية تم فيها الاعتراف ببعض حركات التحرر

الوطني من قبل منظمات دولية وإقليمية باعتبارها سلطة ممنلة للشعوب في نضالها ضد الاستعمار والاحتلال، يرى البعض من الفقه بأن هذا الاعتراف الصادر من تلأك المنظمات الدولية والإقليمية بعتبر شرط إضافي أساسي لتوافر الأهلية للحركة في نطاق المادة ج9 (الفقرة الثالثة) ومن ثم لانطباق أحكام البروتوكول الأول على نسئ نزاعاتها التحريرية. ومن أمتلة تلك الاعترافات، اعتراف منظمة الأمم المتحدة ومنظمة الاتحاد الإفريقي وجامعة الدول العربية بحركة التحرير الفلسطينية.

ولكن، الحقيقة هي أن اعتراف المنظمات الدولية الإقليمية الحكومية لا يعتبر شرط

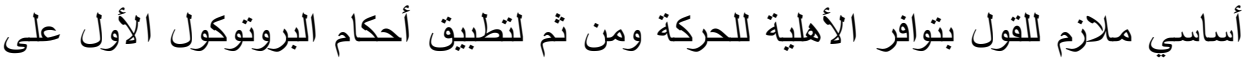
نزاعاتها، بل يمكن قراءة توفره على أنه مجرد افتراض أو مؤشر على تونى توافر الأهلية

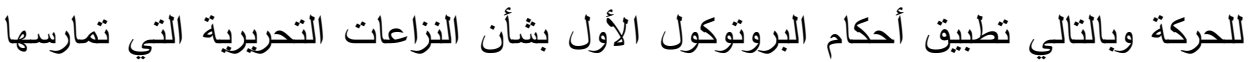
باسم الثعب الذي تمنله ـ ويؤكد ذلك، رفض المقترح التركي وبعض الدول المشاركة في لهي مؤتمر جنيف الدبلوماسي لتعزيز وتطوير القانون الدولي الإنساني بأن يتم اقتصار تطبيق لتوليق

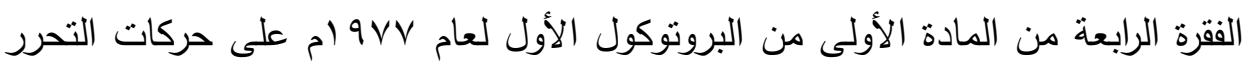




\section{النطاق المادى للقانونزالدولالإنسانم}

الوطنية المعترف بها من قبل المنظمات الإقليمية الحكومية، وأن هذا الاعتراف يكون

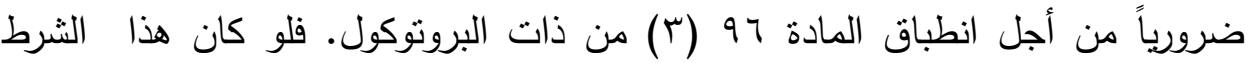

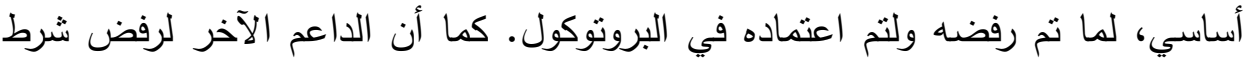

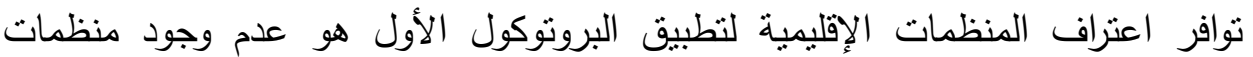
إقليمية حكومية في مناطق جغرافية كثيرة من العالم.

الشرط الرابع: - ممارسة حركة التحرر الوطني السيطرة على جزء من الإقليم الوطني انتراط ممارسة حركة التحرر الوطني السيطرة على جزء من الإقليم الوطني منتقد

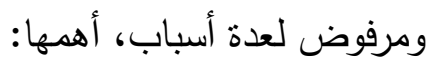

أ - هذا المطلب لا يتتاسب مع ظروف ومنطلبات حرب العصابات المعاصرة، التي

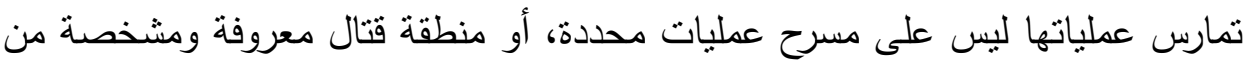

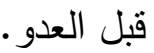

ب - - هذا الثرط يجد أساسه في البروتوكول الإضافي الثاني (الخاص بالمنازعات المسلحة الداخلية) ' ولا يوجد له نظير في البروتوكول الأول، فلو كان هذا الثرط مقبول

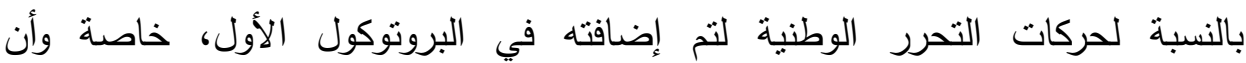

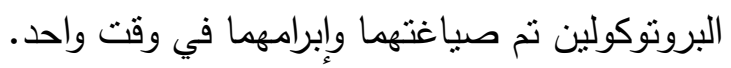

ج - أن اثتراط السيطرة يتنافى مع وضع الدول الخاضعة للاستعمار التي دائما ما

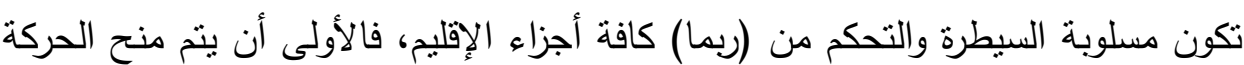
الأهلية ليس استتاداً لواقع سيطرتها على جزء محدد من الإقليم الوطني، وإنما من صفتها، التهاء في المقام الأول، كسلطة تمثل الثعب الساعي لبلوغ حقه في تثرير الدصير بأكمله.

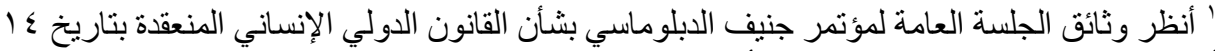

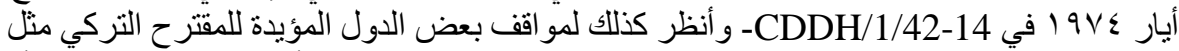

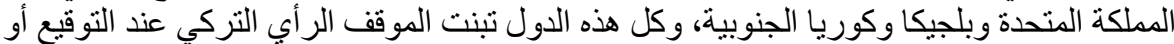

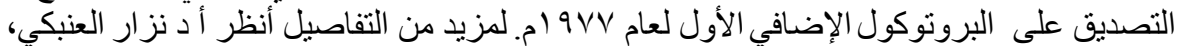

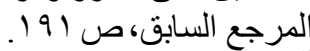

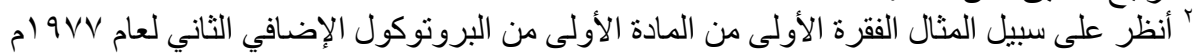

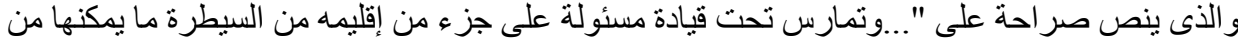
القيام بعمليات عسكرية منو اصلة ومنسقة، وتسنطيع تنفيذ هذا اللحق "البرونوكول". 


\section{المبحث الثاني}

\section{النزاعات المسلحة غير الدولية (الداخلية)}

نتيجة لازدياد النزاعات المسلحة الداخلية بعد الحرب العالمية الثانية والتي لم يكن كل أطرافها دولاً، والتي كانت أثند وحثية وقسوة من بعض النزاعات المسلحة الدولية، فقد كرس المجتم الدولي جهوده لأجل بحث أسباب تلاك النزاعات وأبعادها القانونية والاجتماعية والسياسية وكيفية البحث عن أفضل السبل والحلول لحماية ضحاياها. فكانت

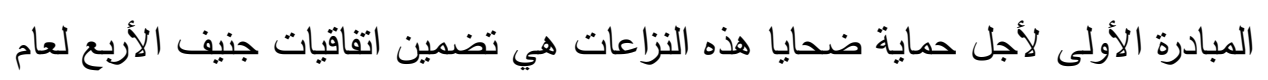

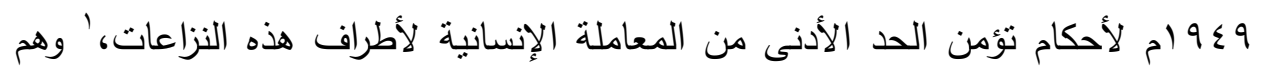

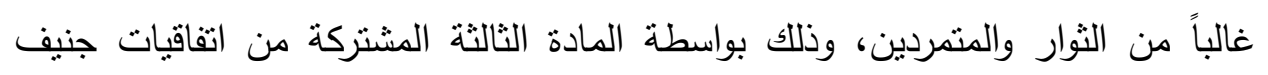

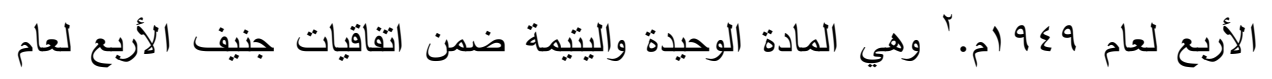

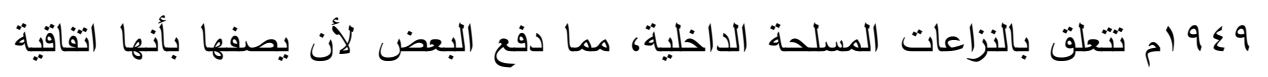

Frits Kalshoven and Liesbeth Zegveld, Constraints on the Waging of War, Cambridge University Press, $4^{\text {th }}$ ed 2011, p. 31.

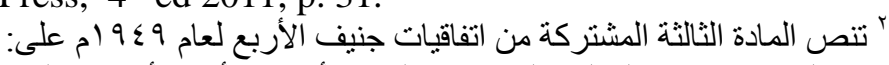

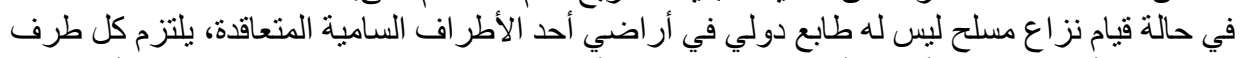

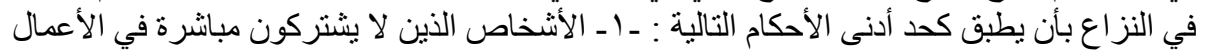

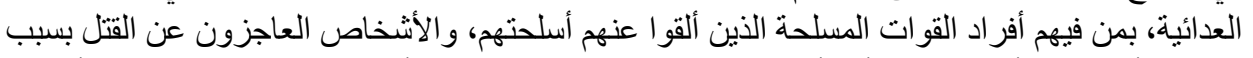

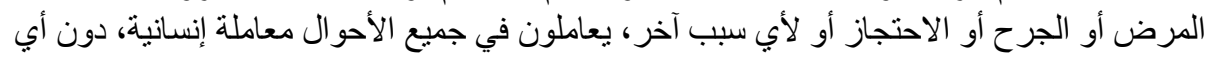

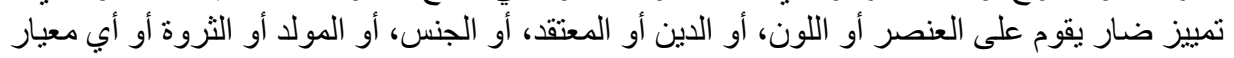

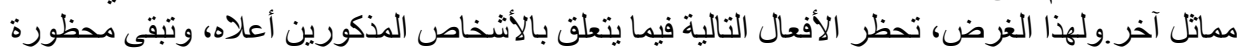

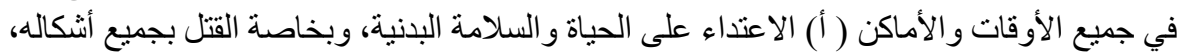

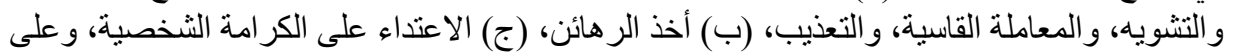

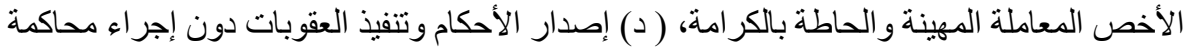

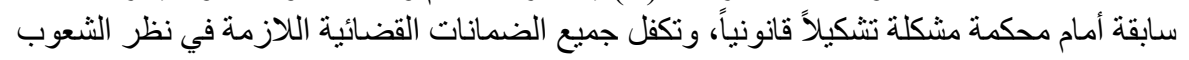

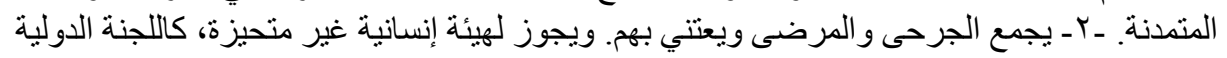

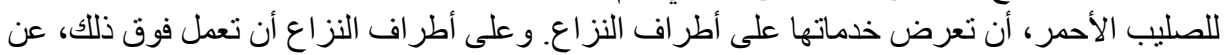

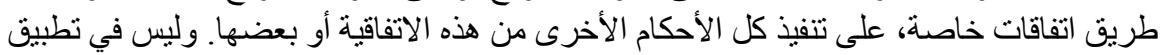

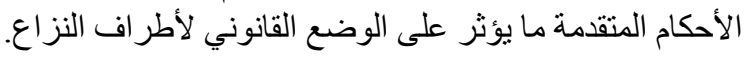




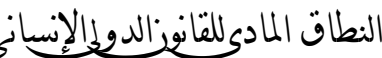

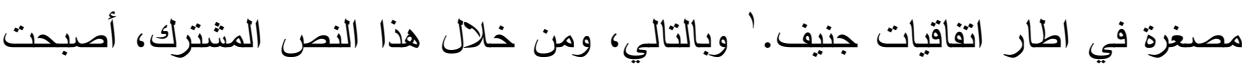
النزاعات الدسلحة غير الدولية خارج نطاق الاختصاص الداخلي للاول، أي أنها أصبحت

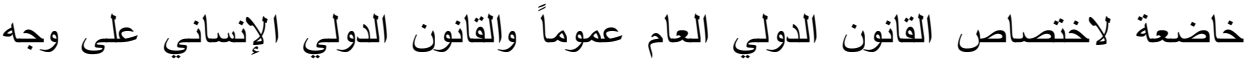

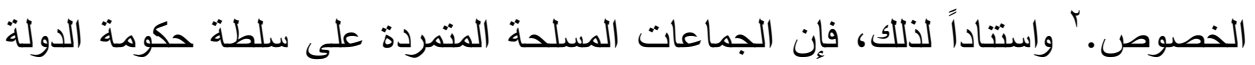
والتي تكون طرف في نزاع مسلح داخلي مع تلك السلطة لا تعتبر قد ارتكبت عملاً جنائياً

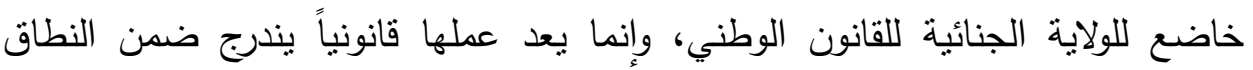
المادي لقانون النزاعات المسلحة الداخلية، ولا يجوز بناء على ذلائك معاملة المتمردين والثوار باعتبارهم مجرمين شقوا عصا الطاعة على الدولة طالما ظلوا ملتزمين باحترام قواعد النزاعات السسلحة ذات الصلة.

وبسبب استمرار الازدياد الملحوظ في وقوع النزاعات المسلحة الداخلية، وعدم كفاية

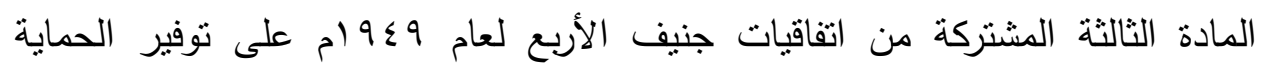
اللازمة لضحايا تلك النزاعات، ونتيجة للجهود المبذولة من اللجنة الدولية للصليب

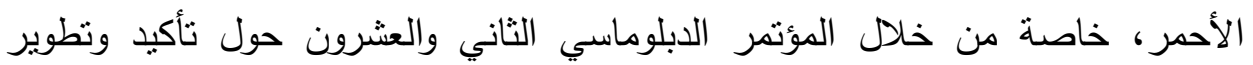

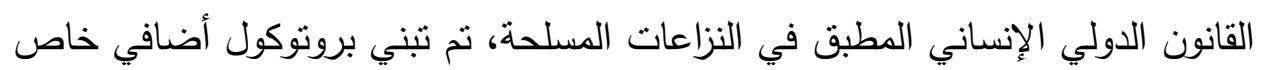

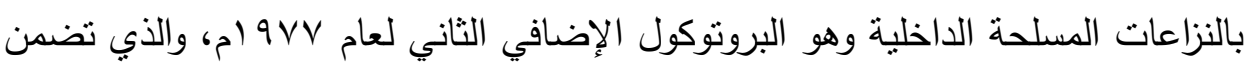
ديياجة و Y مادة كلها تتعلق بحماية ضحايا هذه النزاعات.

والأسئلة التي تثار هي، ما هو الدقصود بالنزاعات المسلحة الداخلية؟ هل نوجد

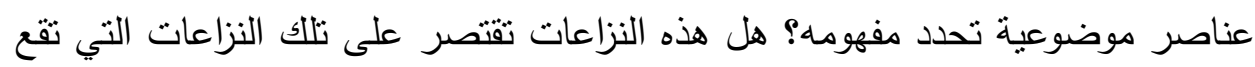
داخل دولة واحدة بين قوات سلطات الدولة وبين جماعات مسلحة، أم تنثمل أيضاً

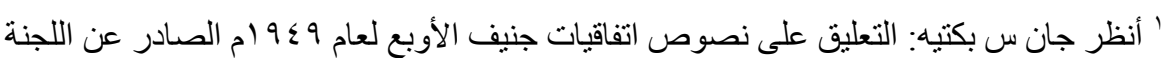

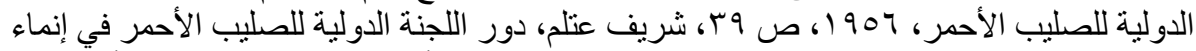

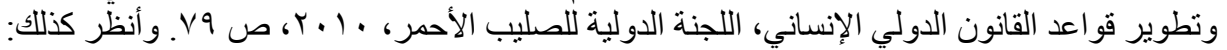

Frits Kalshoven and Liesbeth Zegveld, op.cit, p.67.

Frits Kalshoven and Liesbeth Zegveld, ibid, p.16-17.

(أنظر

د دراثد فهيد المري، الحماية القانونية المقررة لغير المشاركين في النزاعات المسلحة غير الدولية، دار

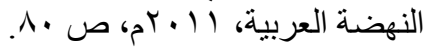


النزاعات التي تقع داخل دولة واحدة بين جماعات مسلحة متتافسة؟ هل لكل مصطلح من المصطلحات التي يتم استخدامها عادة من قبل الفقه لوصف هذه النزاعات المسلحة مثل الحرب الأهلية والعصيان العسكري والثورة والتمرد لها تتظيم قانوني خاص في اطار قانون النزاعات المسلحة الداخلية أم أن جميعها تخضع لذان ولنات التنظيم القانوني وتعد جميعها صور من صور النزاعات المسلحة الداخلية؟ ما هو الحد الفاصل بين هذه النزاعات المسلحة الداخلية الخاضعة لأحكام قانون النزاعات المسلحة الداخلية وبين مجرد الاضطرابات والتوترات الداخلية الخارجة عن اختصاص هذا القانون؟ الإجابة على هذه الأسئلة تتم من خلال التعرف على مضمون النزاعات المسلحة الداخلية، لذا فإنه سيتم في الجزء التالي من البحث تحليل ونقاش الأحكام المتعلقة بمفهوم

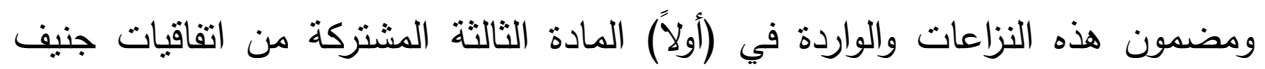
الأربع (وثانياً) في المادة الأولى من البروتوكول الإضافي الأول لعام 9VV ام. وعليه، فإنه سيتم تقسيم هذا المبحث إلى مطلبين، يتتاول الأول مضمون النزاعات المسلحة

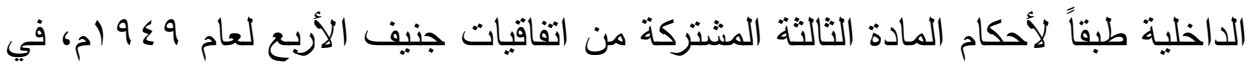

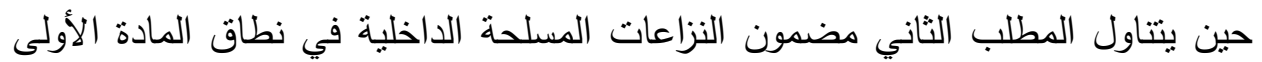
من البروتوكول الإضافي الثاني لعام 9VV ام. 


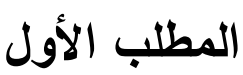

\section{النزاعات المسلحة الداخلية في نطاق المادة الثالثة المشتركة من \\ اتفاقيات جنيف الأربع لعام 9 \& 9 ام'}

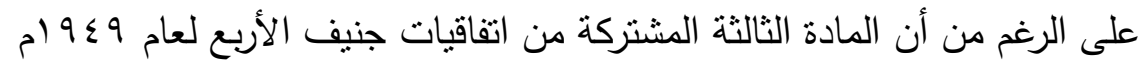
تعتبر المادة الوحيدة المعنية بالنزاعات المسلحة الداخلية والتي تتكل مدونة إلزامية واجبة النية التطبيق كحد أدنى في النزاعات المسلحة الداخلية، ‘ إلا إنها صدرت خالية من أبي إثنارة

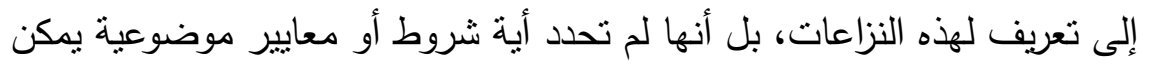

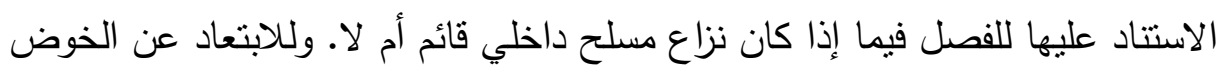
في اثكالية التعريف أو تحديد تلك المعايير والثروط الموضوعية، اكتقت المادة بالقول بأن نطاقها المادي يسري على كل "نزاع مسلح ليس له طابع دولي". أي أنه، ووفقاً لهذا التعريف السلبي، فإن كل نزاع مسلح لبس بدولي، أي ليس من ضمن أباً من الصورثين

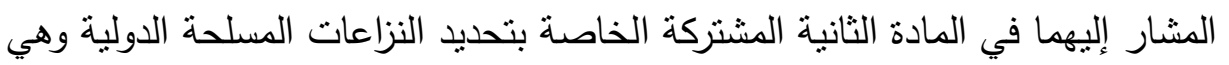

(1) حالة الحرب المعلنة أو أب اشتباك مسلح آخر ينشب بين طرفين أو أكثر (r)

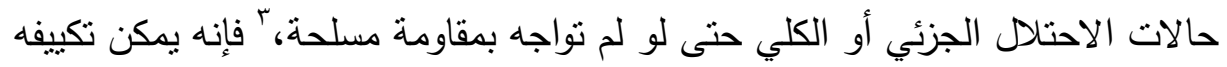

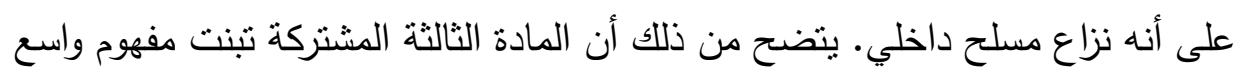

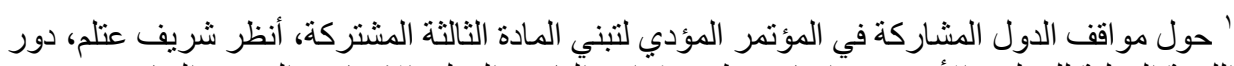

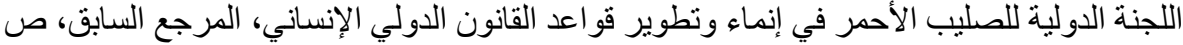
. $\vee q_{-1} \vee v 1$

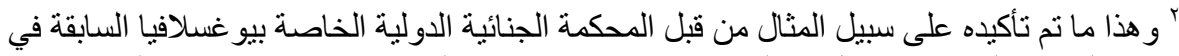

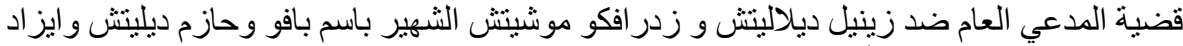

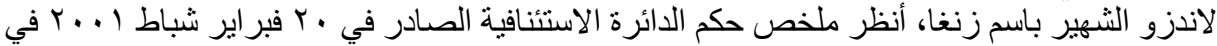

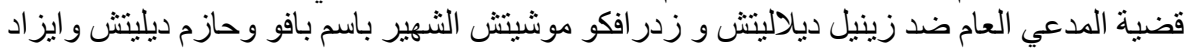

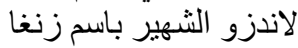

Zejnil Delalic, Zdravko Mucic (a-k-a Pavo), Hazim Delic, Esad Landzo (a-k-a

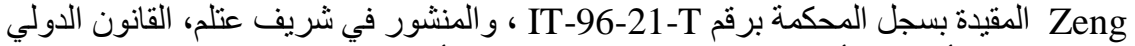

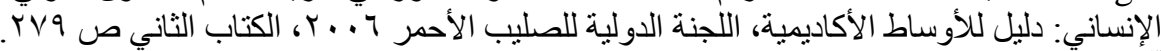

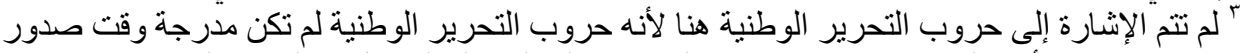

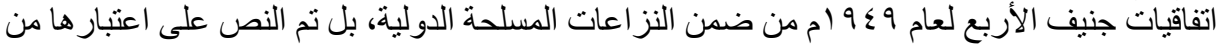

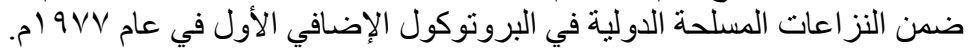


للنطاق المادي للنزاعات المسلحة الداخلية، بحيث يمكن تكييف كل نزاع ليس بدولي على

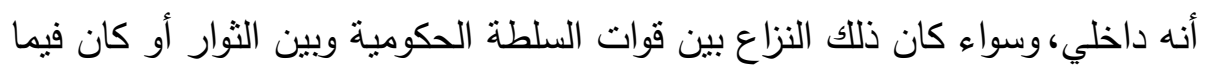
بين الجماعات المسلحة وبدون تورط القوات الحكومية. كما أنه، وبحكم عدم وجود معايير

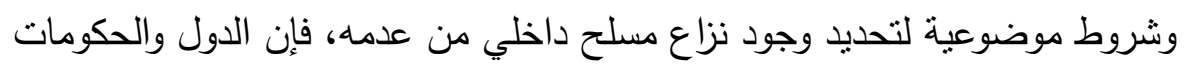
تكون لها سلطة تقديرية واسعة في تقدير وجود أو نفي وجود ذلك النزاع. في الحقيقة، برزت عدة محاولات وقدمت عدة اقتراحات من قبل مندوبي الدول

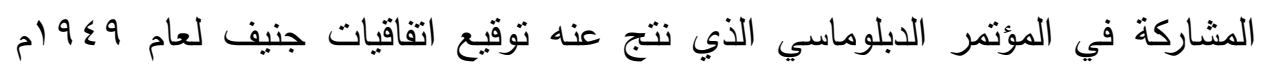

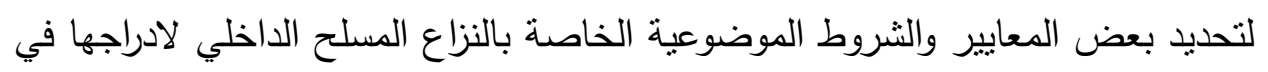
تعريف محدد، لكن الصيغة النهائية للمادة جاءت خالية من ذلك بهدف تجاوز نفرة الدول

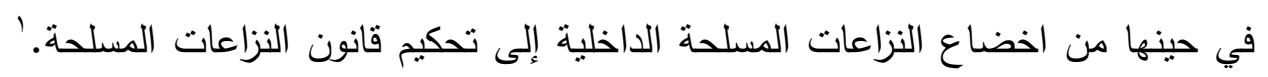
ومن أهم تلك الاقتراحات:

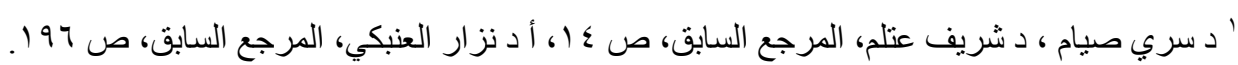

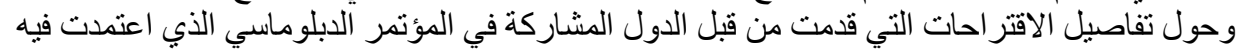

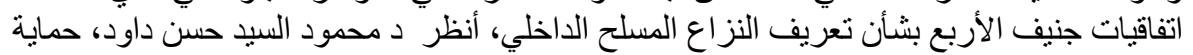

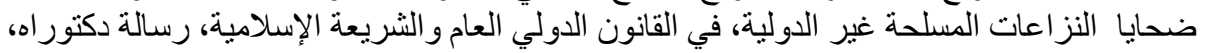

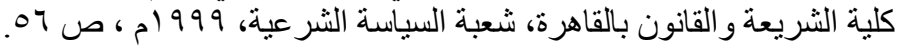


حيازة الطرف المتمرد على الحكومة الثرعية قوات مسلحة منظمة، وسلطة مسئولة عن

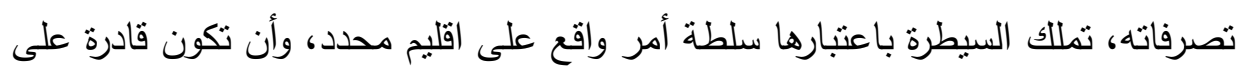
احترام وكفالة احترام الاتفاقيات.

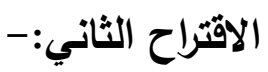

أن تكون الحكومة الشرعية مجبرة على استذعاء قواتها المسلحة النظامية لمقاتلة المتمردين المنظمين عسكرياً والذين يمارسون السيطرة العسكرية على اقليم وطني محدد.

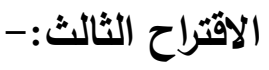

اعتراف الحكومة الثرعية للمتمردين بصفة المحاربين، أو أن يدعي المحاربين

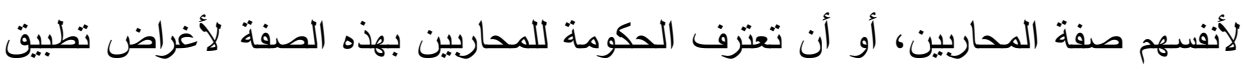

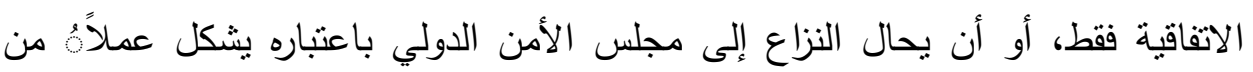
أعمال العدوان أو التهديد أو الإخلال بالئل فئلم والأمن الدوليين.

لاحقاً على تبيني اتفاقيات جنيف الأربع لعام 9 ام ام استمرت المحاولات لوضع

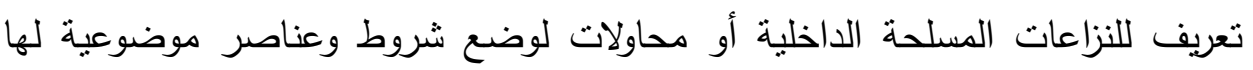

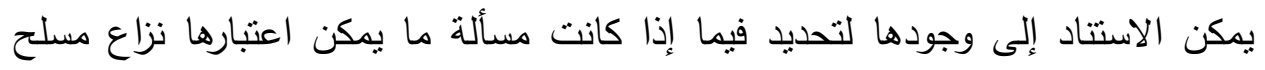
داخلي خاضع لأحكام المادة الثالثة المشتركة أم لا. أهمها، محاولات اللجنة الدولية

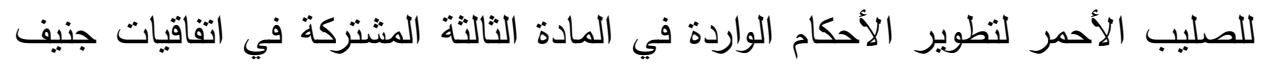
9 9 1م، وذللك عندما دعت إلى عقد عدة لجان لدراسة وتطوير بعض المسائل المتعلقة بالنزاعات المسلحة غير الدولية، ومن أهم تلك اللجان: أولاً: لجنة الخبراء المكلفة بدراسة "مسألة تطبيق المبادئ الإنسانية في حالة

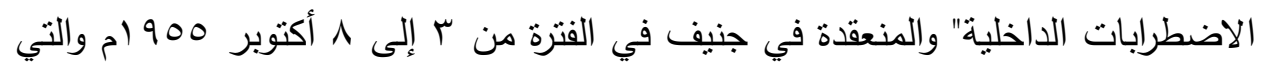
انتهت إلى اعتبار الاضطرابات الداخلية خارجة من اختصاص المادة الثالثة المشتركة ولا

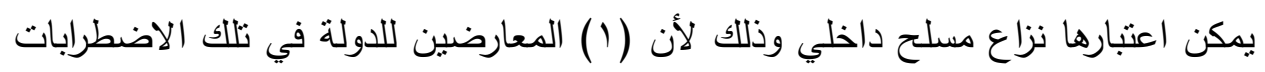


داد سيف غانم السويدى

يكونوا أفرادا من رعاياها ولا يشكلون مع الحكومة طرفاً في نزاع، (r) أن الاضطرابات الداخلية تتكرر بشكل مستمر في دول العالم، لذا يجب المحافظة على حق تلك الدول في تقدير تلك الأوضاع لمعاقبة الخارجين عليها والمنظمين لتلك الاضطرابات بشرط مراعاة المبادئ الإنسانية وقواعد حقوق الإنسان المتعارف عليها قانوناً.'

ثانباً: لجنة الخبراء المكلفة بدراسة "مسألة مساعدة النزاعات الداخلية، والمنعقدة في

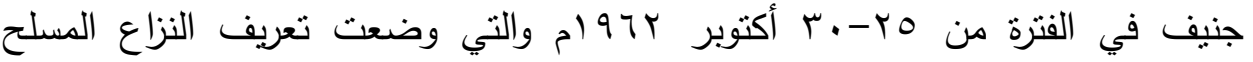
الداخلي كمسألة أولى ضمن جدول أعمالها. وانتهت هذه اللجنة إلى أنه من الضروري أن يخضع تعريف النزاع المسلح الداخلي لثروط موضوعية، لا لتقدير الدولة التي يقع النزاع

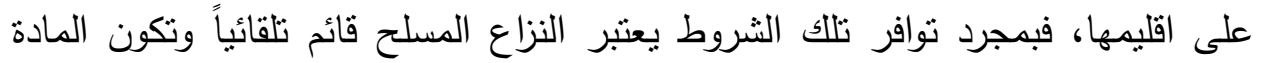

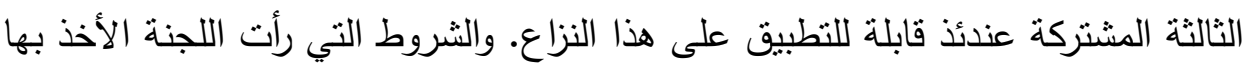
في الاعتبار هي ما يتعلق بمدة النزاع والطابع الجماعي والتنظيمي ودرجة التمرد ووجود

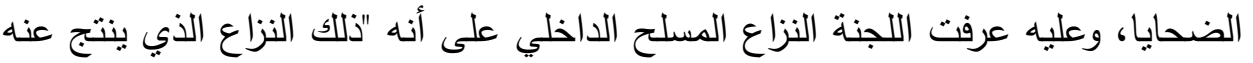

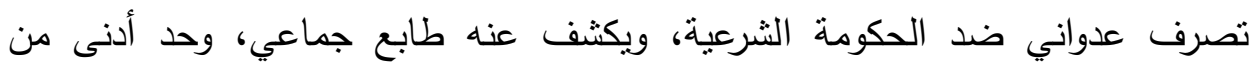

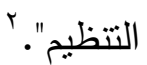

كما أن الفقة والعمل الدوليين كان لهما دور في محاولة بيان وتوضيح الثروط والعناصر الموضوعية المقبولة دولياً للفصل في نوافر نزاع مسلح داخلي من عدمه لنه

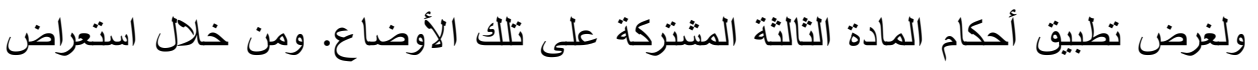
التعريفات المقدمة من قبل الققه نجد أنهم قد اتفقوا على ضرورة توافر شرطين موضوعيين

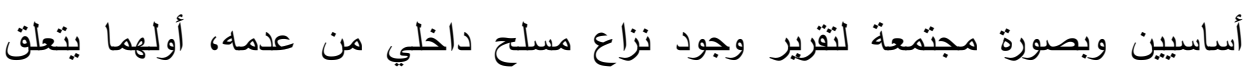
بالكثافة والثدة كأي نزاع مسلح تثواجه فيه قوات مسلحة، وثانيهما خاص بدرجة التنظيم للجماعة المسلحة والتي تتطلب توافر قيادة مسؤولة للجماعة المسلحة قادرة على احترام وكفالة احترام الاتفاقيات.

' تقرير لجنة الخبر اء المكلفة بدر اسة مسألة تطبيق المبادئ الإنسانية في حالة الاضطر ابات الداخلية،

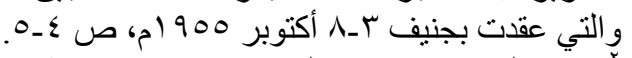

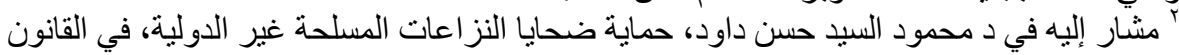

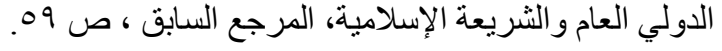


فمثلاً، يعرف الاستاذ الدكتور نزار العنكبي النزاع المسلح الداخلي على أنه "كل نزاع

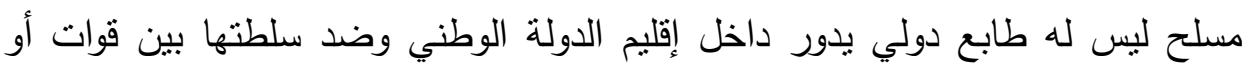

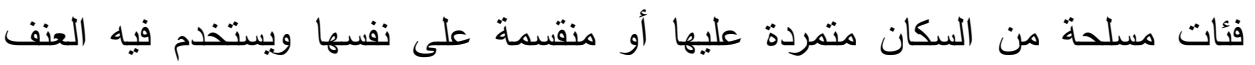
المسلح، على الجانبين، بدرجة من الكثافة والثدة تجعل منه أكثر من مجرد تمرد فوضوي

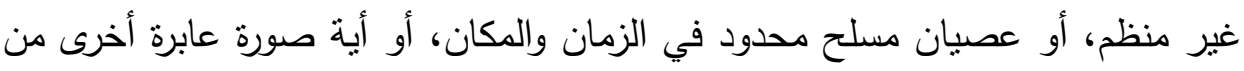

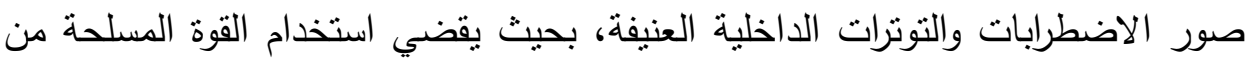
قبل المتمردين على سلطة الدولة أو من قبل الفئات المنقسمة على نفسها إلى ممارسة

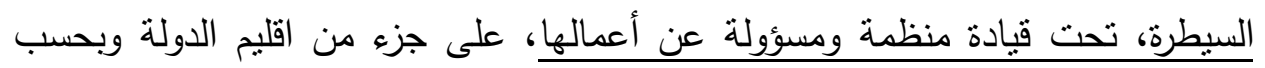

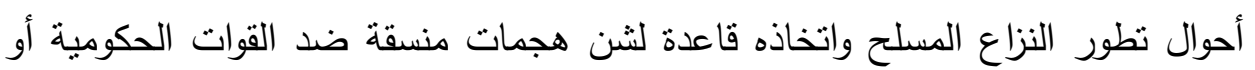
فيما بينها وفي ظل احترام تام لقوانين وأعراف الحرب النافذة في مجال هذا النوع من هن

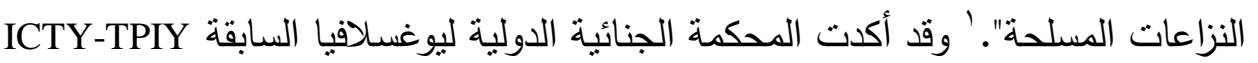
في حكمها في قضية تاديتج 99 Tadic-1990 197، وهي أول قضية تتظر أمام محكمة يوغوسلافيا السابقة، على ضرورة نوافر هذين الثرطين - الكثافة والتتظيم - باعنبارهما

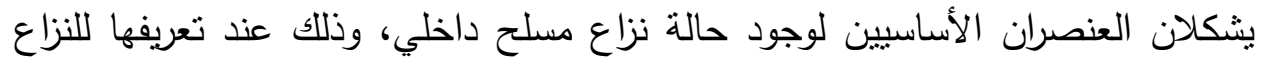
السلح وبيانها بأنه يعتبر قائم "متى تم اللجوء لاستعمال القوة بين الدول، أو قيام أعمال عدائية مطولية (للالالة على الكثافة والثدة) بين قوات السلطة الحكومية وبين جماعات مسلحة منظمة أو بين تلاك الجماعات في داخل الدولة". ب ولا جدال في تأييد كلا

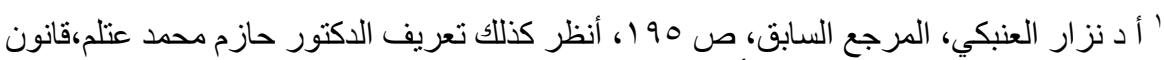

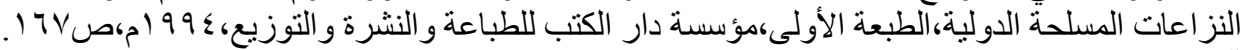

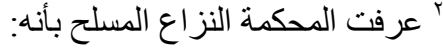
"an armed conflict exists whenever there is a resort to armed force between States or protracted armed violence between governmental authorities and organized armed groups or between such groups within a State".

الترجمة غير الحرفية: "يعتبر النزاع المسلح قائم منى تم اللجو الاستعمال القوة بين الدول، أو قيام أعمال

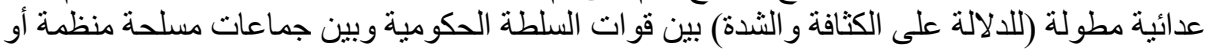
بين تلك الجماعات في داخل الدولة".

The prosecutor. V. Tadic, 2 October 1995, Case. No. IT-94-1-AR 72 (Appeals Chamber, ICTY) 37-8 para. 70 (Decision on the Defense Motion for interlocutory Appeal on Jurisdiction). The prosecutor V Tadic (opinion and judgment) 7 May 1997, Case. No-IT, 94-1-T (Trial Chamber 11, ICTY) para. 564. 
د د سيف غايم السويدى

الثرطين، فشرط الكثافة والثدة يعتبر ضروري لأن بدونه يمكن انطباق حالة النزاع

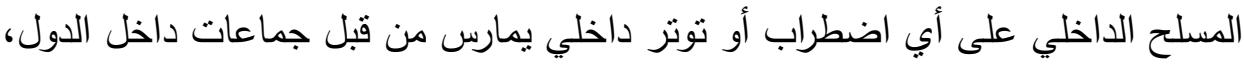

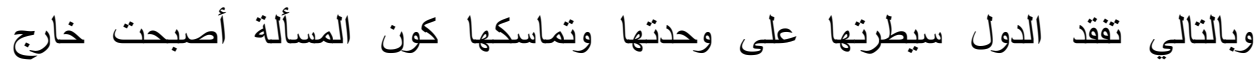
اختصاص قوانينها الوطنية ودخلت ضمن اختصاص القانون الدولي الإنساني الذي بلزمها بالتعامل مع الخارجين عليها باعتبارهم أصحاب حق وباعنبارهم طرف موازي لسلطة الدولة، وهذا بالطبع سيؤثر على استقلال وسيادة الدول. أما فيما يتعلق بشرط التنظيم الذي يجب أن تكون عليه الجماعة المسلحة والذي يتطلب أن تكون تلك الجماعة خاضعة

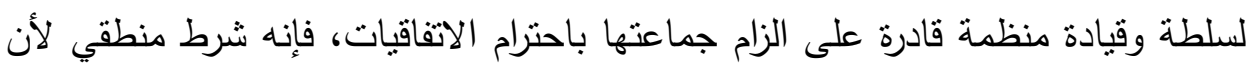

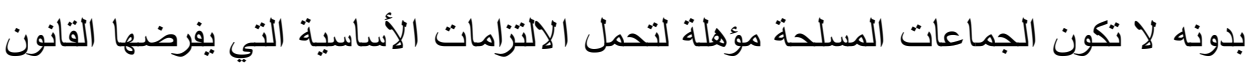
الدولي الإنساني، ولأن بغيابه تتحول النزاعات إلى أعمال فوضية واقعة كل البعد خارج النتظيم القانوني الذي يهدف إلى أنسنة النزاعات وليس إلى زيادة وحثينها. عموماً، فإنه، وبسبب عدم اعتماد هذه الاقتراحات في أية اتفاقية دولية كاتفاقيات جنيف الأربع لعام 9 9 ام فإنها جميعاً تبقى مجرد اقتراحات ليس لها الطابها لهابع الإلزامي. وبالتالي، يترك المجال واسعاً أمام سلطات وحكومات الدول لاستخدام سلطاتها التقديرية لتحديد قيام نزاع مسلح داخلي على أقاليمها ومن ثم تقرير مدى جواز انطباق أحكام المادة

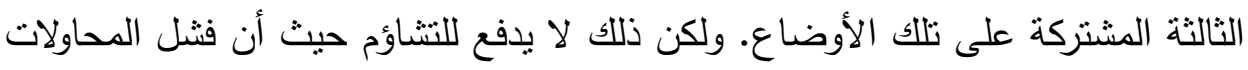
السابقة الرامية لوضع تعريف موضوعي للنزاع المسلح الداخلي مهدت الطريق لمناقشات

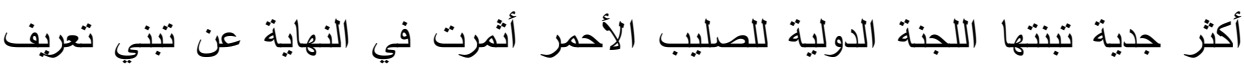

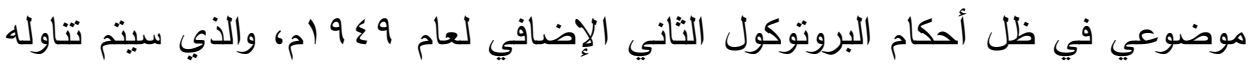
بالتقصيل في المطلب التالي.

ولمزيد من القضايا والتطبيق المؤيد لضرورة تو افر هذه الثروط أنظر:

Frits Kalshoven and Liesbeth Zegveld, op.cit., pp. 11-12. 


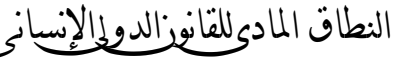

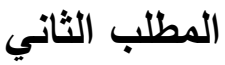

\section{النزاعات المسلحة الداخلية في نطاق المادة الأولى من البروتوكول الثاني

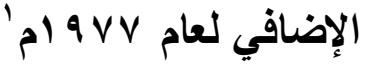

طبقاً للفقرة الأولى من المادة الأولى للبروتوكول الثاني الإضافي لعام 9VVام فإنه

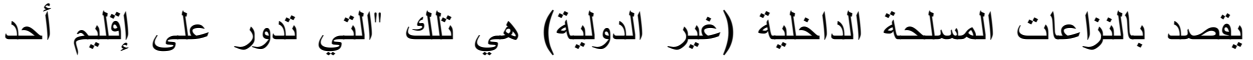

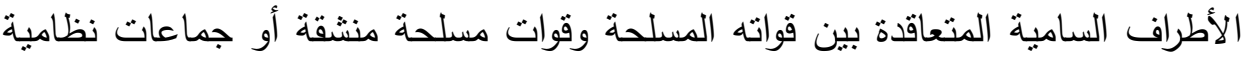
مسلحة أخرى وتمارس تحت قيادة مسئولة على جزء من إقليمه من السيطرة ما يمكنها من القيام بعمليات عسكرية متواصلة ومنسقة، وتسنطيع تتفيذ هذا اللحق "البروتوكول". وطبقاً كلذا النص فإن النطاق المادي للبروتوكول الثاني يسري بشكل حصري على

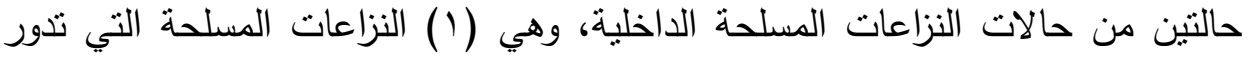

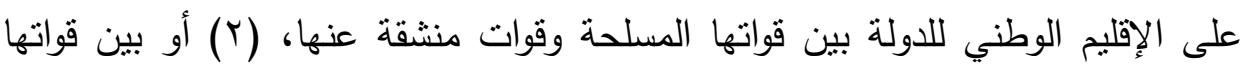
المسلحة وأية جماعات نظامية مسلحة أخرى متمردة عليها. وبالتالي، فإن أحكام البروتوكول الثاني تكون غير قابلة للنطبيق على النزاعات المسلحة الداخلية الني لا تكون

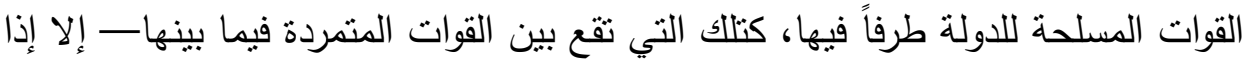

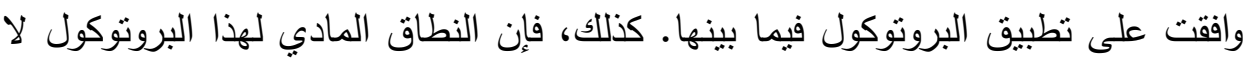

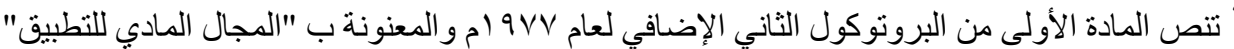

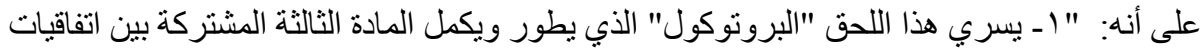

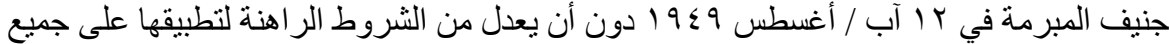

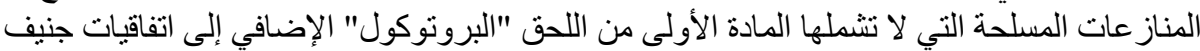

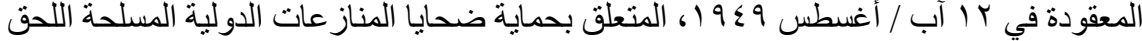

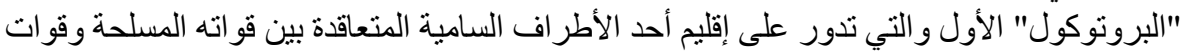

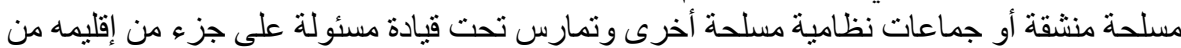

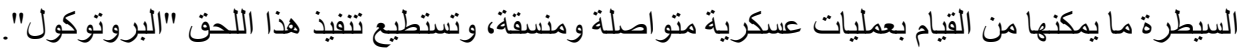

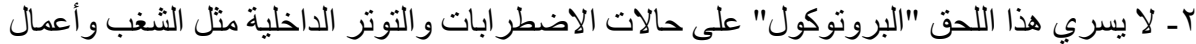

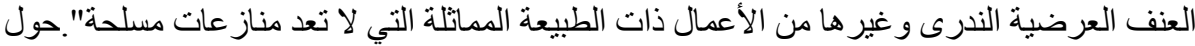

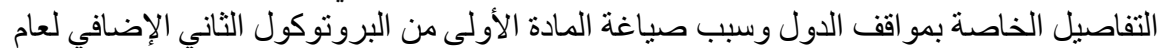

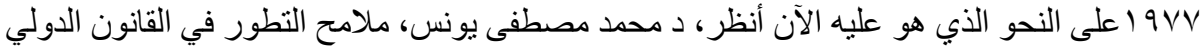

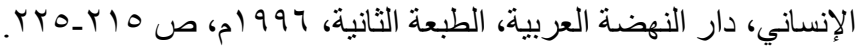


د / سيف غانم السويدى

تكون قابلة للنطبيق على النزاعات المسلحة التي لا تتوافر للجماعة المسلحة التي تقاتل

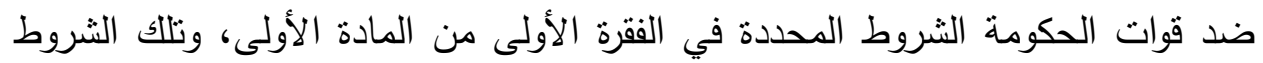
هي: (1) شرط التنظيم وأن تكون لها قيادة مسئولة تسنطيع فرض احترام القانون الدولي

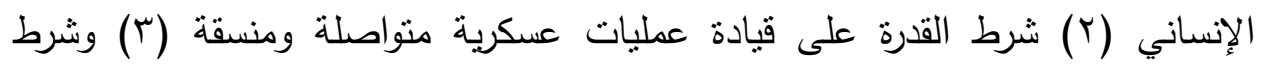
السيطرة على جزء من الاقليم الوطني للدولة.'

ويستخلص من حكم هذه المادة، أن هناك شروط موضوعية يجب نوافرها بصورة مجتمعة في النزاع المسلح كي يعتبر نزاع مسلح داخلي قابل لانطباق أحكام البروتوكول الثاني عليه، وهذه الثروط هي: الشرط الأول: أن تتورط الدولة وقواتها المسلحة في النزاع فطبقاً لهذا الثرط، فإن أي نزاع مسلح لا تتورط فيه القوات المسلحة النظامية للدولة

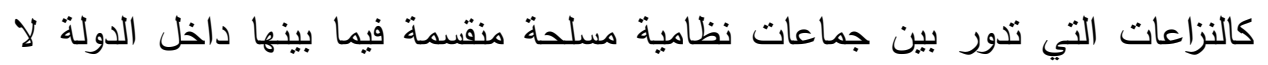

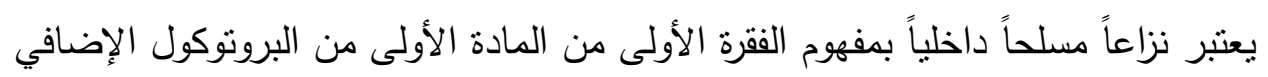

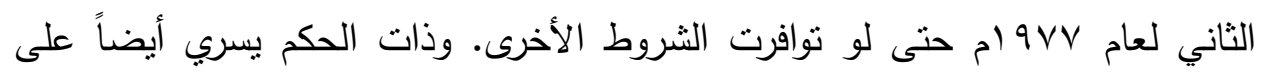
الأوضاع التي تتمكن فيها الدولة من انهاء التمرد المسلح بوسيلة أخرى غير اللجوث لاستدعاء قواتها المسلحة. ومثل هذه النزاعات المسلحة التي تقع بين جماعات مسلحة داخل إقليم الدولة الواحدة دون أن تكون القوات المسلحة للدولة طرفاً فيها تكون قابلة للاندلاع في حال كانت الدولة مفككة والحكومة ضعيفة، وذلك كما كان الحال بالنسبة

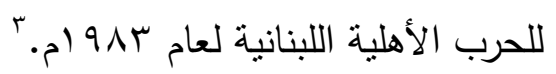

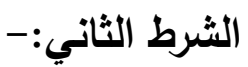

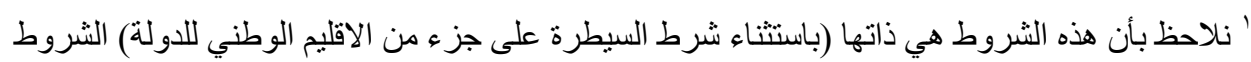

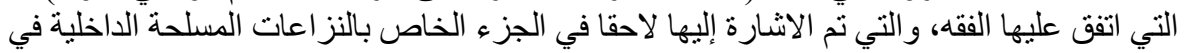

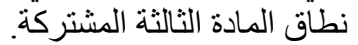

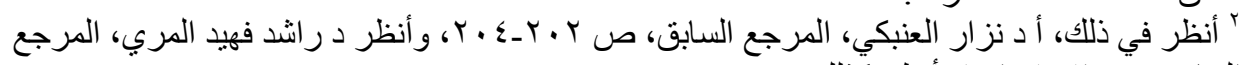
Frits Kalshoven and Liesbeth Zegveld, op.cit., pp. 143-144.

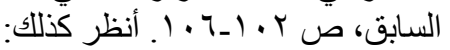
r د سعيد سالم جويلي، المرجع السابق، ص . . r. 
أن تكون للجماعة المسلحة التي تقاتل ضد الحكومة درجة من التتظيم ولها قيادة مسئولة أكدت المحكمة الجنائية الدولية الخاصة بيوغوسلافيا السابقة في حكمها في قضية تاديتش Tadic على ضرورة وجود عنصر التتظيم للجماعة|المسلحة، فبدون وجود حد أدنى من التتظيم للجماعة المسلحة المتمردة على سلطة الدولة فلن تكون هذه الجماعة وجله

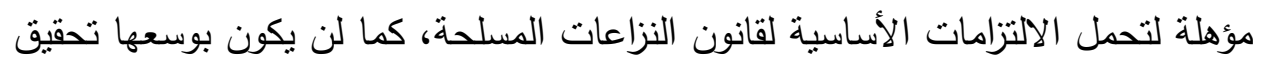
الاشتراطات الأخرى الموضحة في ذات المادة وهي قيادة عمليات عسكرية متواصلة

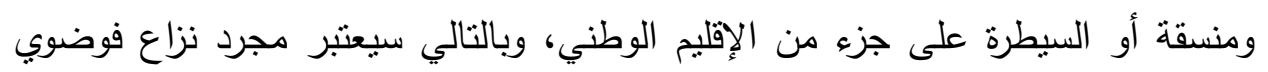

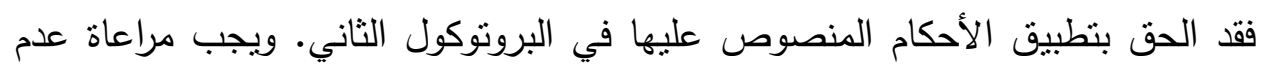

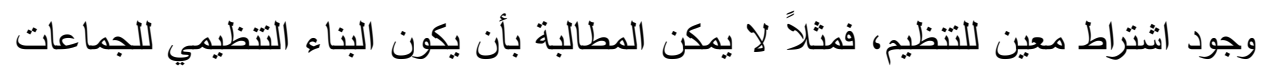

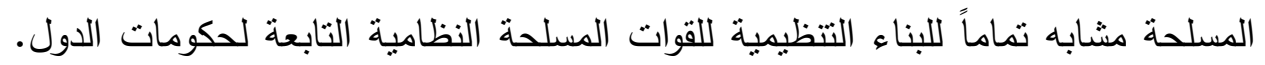
ويتم تقدير وجود التنظيم بناء على كل حالة على حدة، ويكون من خلا تقدير وجود عوامل وعناصر معينة كوجود هيكل قيادي منظم ودقيق، السيطرة على جزء من اقليم

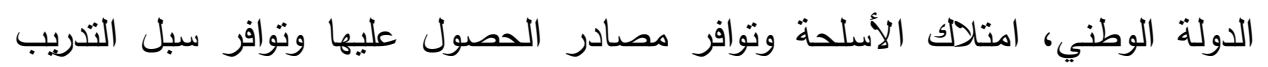

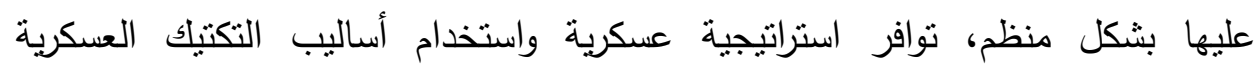
المتعارف عليها. وهذا ما نم تأكيده من قبل المحكمة الجنائية الدولية الخاصة بيوغوسلافيا

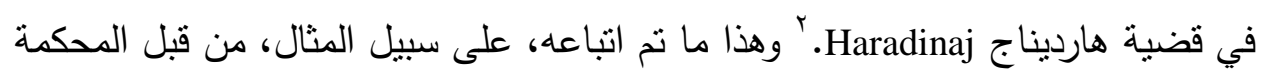

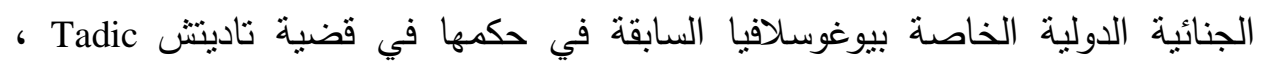

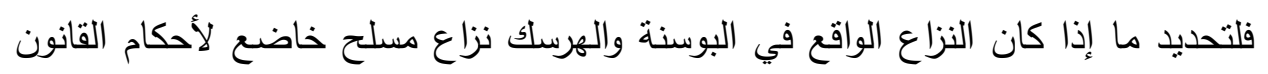

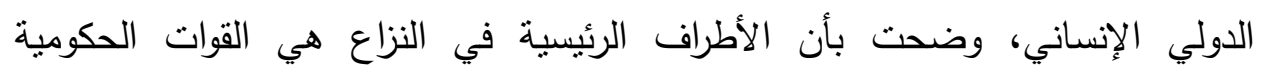
لجمهورية البوسنة والهرسك وبين وقوات صرب البوسنة، وبينت بأن قوات صرب البوسنة

The prosecutor v. Tadic (Appeal on jurisdiction) 2Oct. 1995, case n 1T.94-1AR72 (Appeal chamber, ICTY) at 37 Para. 70

$$
\text { r حيث أكدت المحكمة على أنه من أهم الدلائل والمؤشر ات على وجود التظظيم هي: }
$$

"the Existence of command structure and disciplinary rules; control of a determinate territory; access to weapons, equipment and military training; and the ability to define military strategy and use military tactics". Prosecutor v Haradinaj, ICTY Trial Chamber Judgment, 3 April 2008, p 60. 
د د سيف غانم السويدى

كان لها قدر كبير من التظيم الذي تم الاستدلال عليه من خلال وجود تتظيم إداري

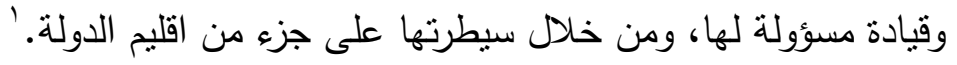

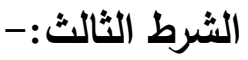

أن تكون للجماعات المسلحة القدرة على قيادة عمليات عسكرية منواصلة ومنسقة أي أن تكون للجماعات المسلحة المتمردة القدرة على شن عمليات عسكرية جماعية منسقة تتصف بالثدة وبالايمومة، وعليه يتم استبعاد الأعمال المنعزلة والمتفرقة والفوضوية التي يمكن إدراجها ضمن مفهوم الإضطرابات والتوترات الداخلية المستبعدة بموجب حكم الفقرة الثانية من المادة الأولى للبروتوكول الإضافي الثاني من النطاق

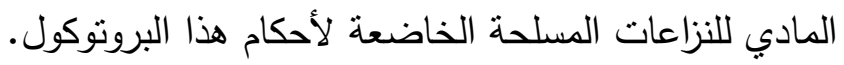

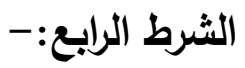

أن تمارس القوات أو الجماعات المتمردة السيطرة على جزء من الإقليم الوطني:

هذا الثرط الذي يجد أساسه في قوانين وأعراف الحرب التقليدية يتسم بالغموض حيث يصعب وضع معيار موضوعي يحدد بدقة مدى السيطرة التي تمارسها الجماعة

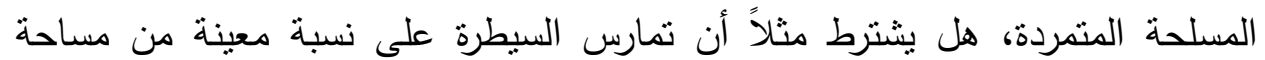

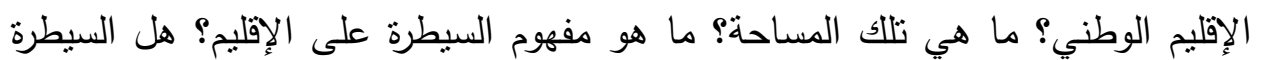

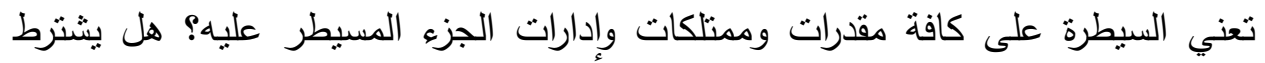
خضوع سكان ذلك الجزء لسلطة الجماعة المسلحة؟ وغيرها من الأسئلة الكثيرة التي تثار بشأن تلك السيطرة. بالرغم من ذلك، أقر مؤتمر جنيف الدبلوماسي المؤدي لتبني

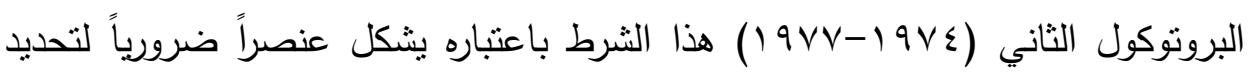

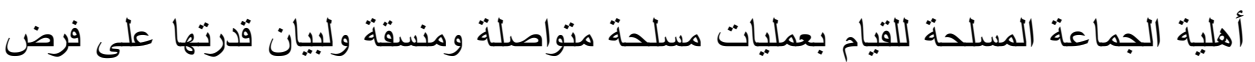
احترام أحكام القانون الدولي الإنساني.

' أنظر : The prosecutorv.Tadic, ICTY TrialChamber Judgment,7May 1997(564) (567) 
ويترتب على فرض الفقرة الأولى من المادة الأولى للبروتوكول الإضافي الثاني لهذه

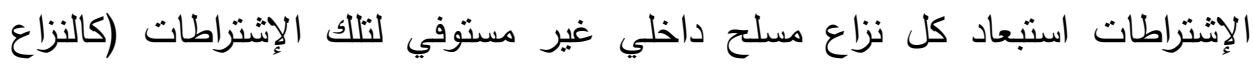

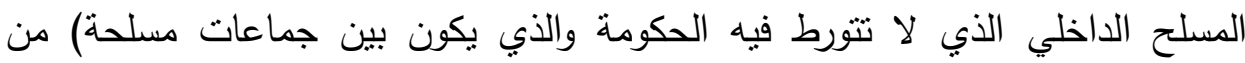
الخضوع للنطاق المادي للبروتوكول إلا إذا وافق أطراف النزاع المسلح على انطباق أحكام

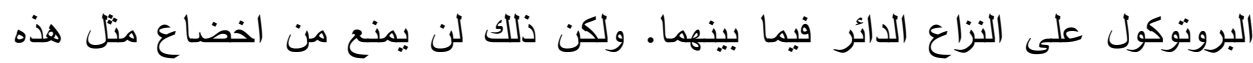

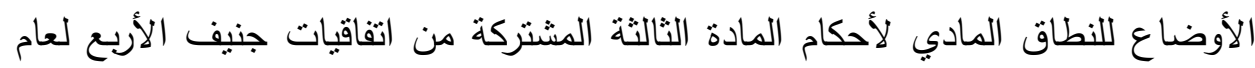
9 9 ام عليها، فأحكام المادة الثالثة المشتركة المكتسبة للصفة القانونية العرفية تظل الطان

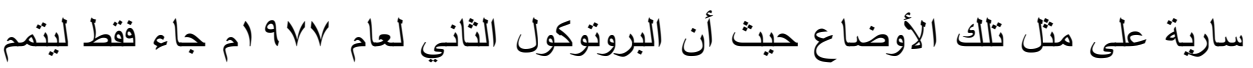

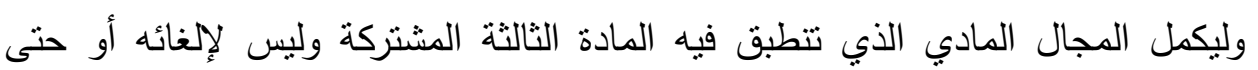

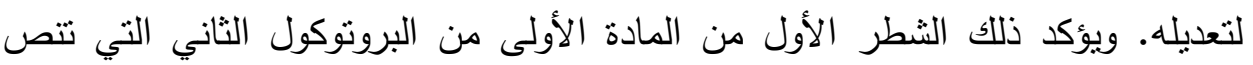
على "يسري هذا اللحق "البروتوكول" الذي يطور ويكمل المادة الثالثة المشتركة بين الثين

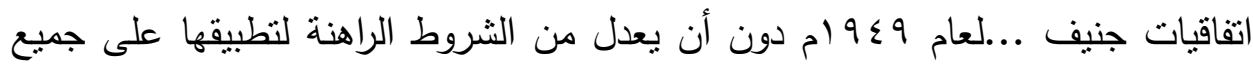

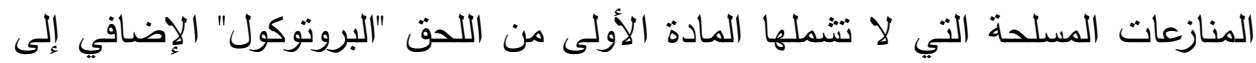

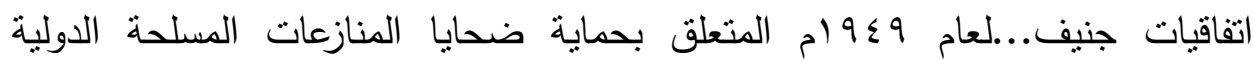

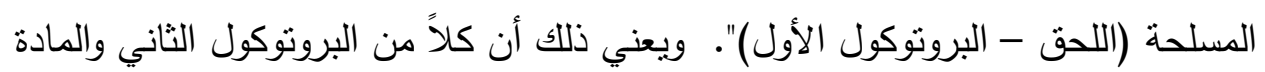

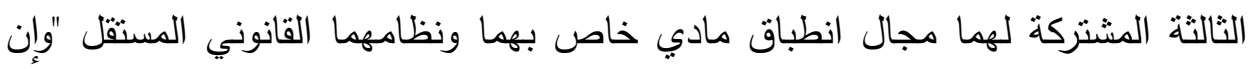

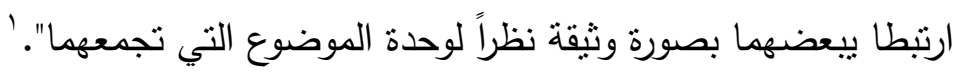

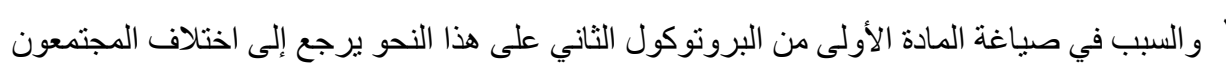

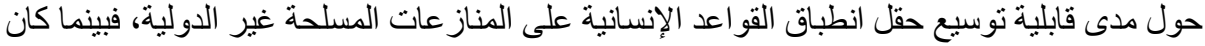

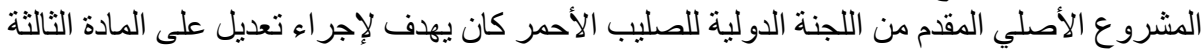

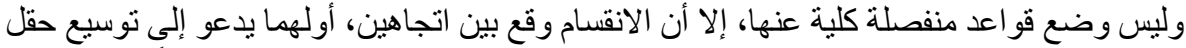

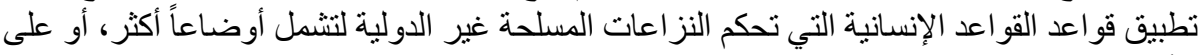

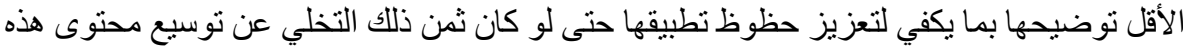

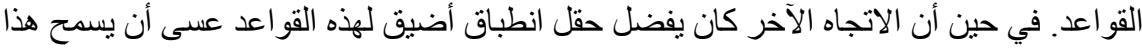

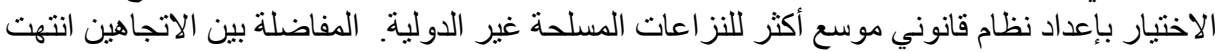

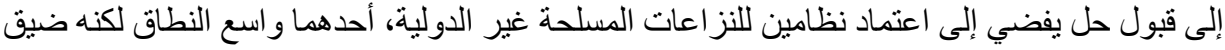

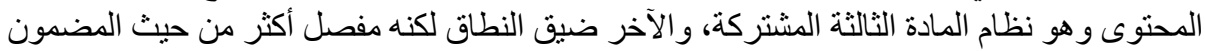

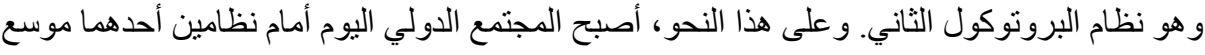




\section{المبحث الثالث}

\section{النزاعات المسلحة المدولة}

النزاعات المسلحة وفقاً للتقسيم الوارد في نصوص اتفاقيات القانون الدولي الإنساني

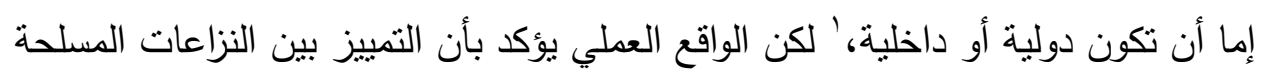

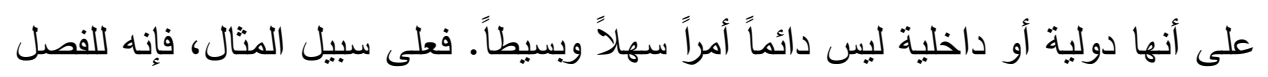

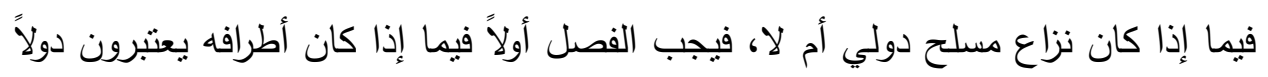

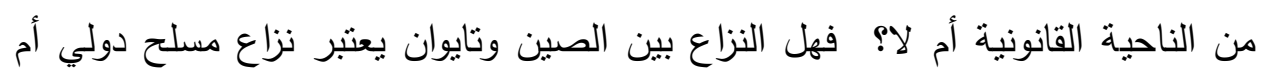
داخلي؟ لاشك أن الإجابة على ذلك يتوقف على مدى اعتبار تايوان دولة تتوافر لها أركان

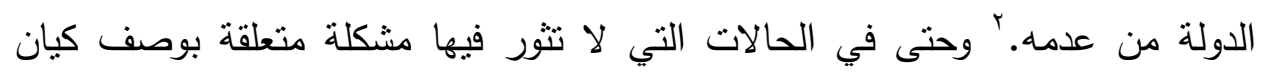
معين باعتباره دولة من عدمه، فإن بعض النزاعات قد تتورط فيها جماعات مسلحة

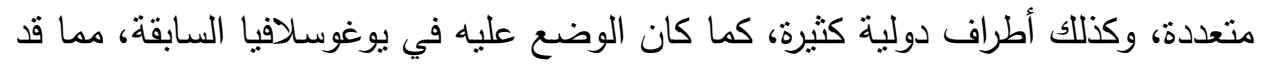

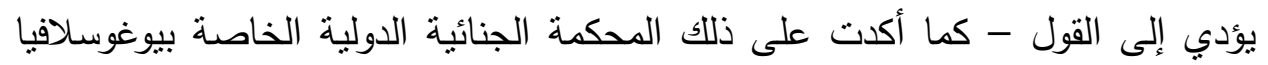

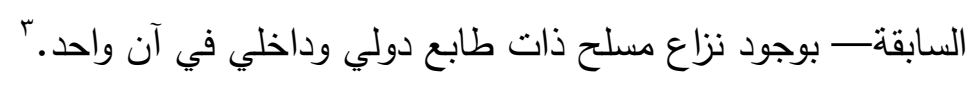

للنطاق المادي غير محدد المعايير (نظام المادة الثالثة المشتركة لعام 9 ؟ 9 (م) ، و والأخر محدد المعالم

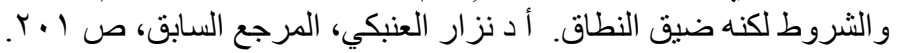

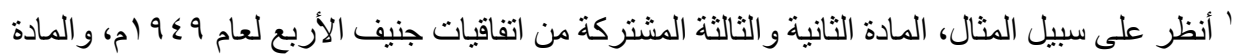

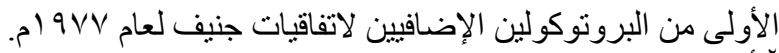
Jonathan Crowe \& Kylie Weston-Scheuber, op.cit. p.19.

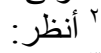

The prosecutor v. Tadic ICTY Appeals Chamber Decision on Jurisdiction, 2 October 1995 (77).

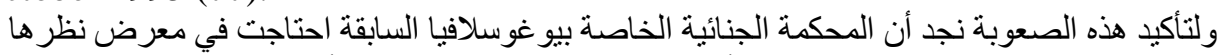

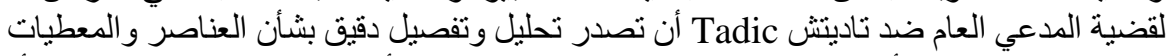

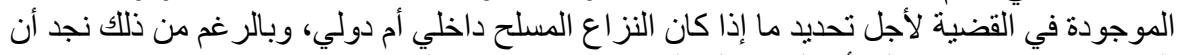

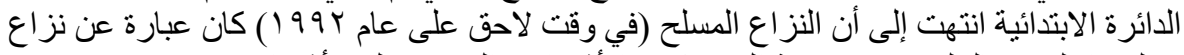

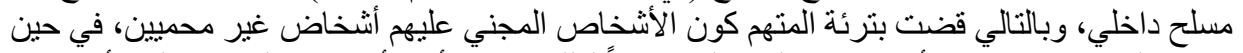

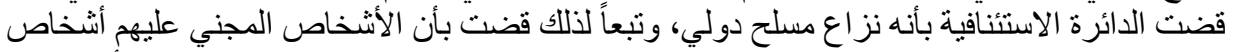

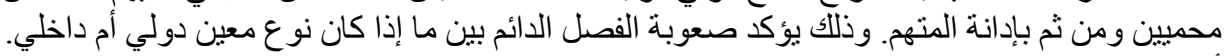

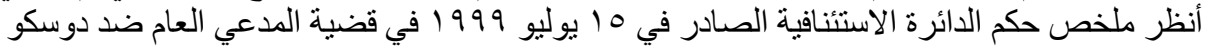

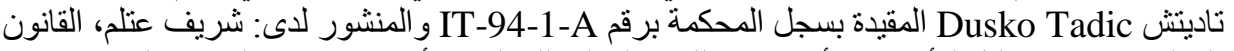

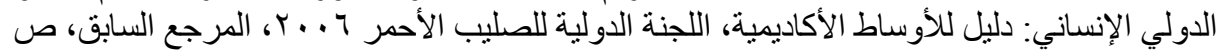


إن الواقع العملي فرض وجود نوع ثالث من النزاعات المسلحة ينعارف عليها باسم

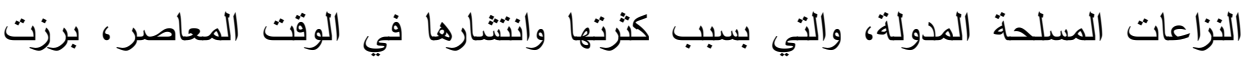

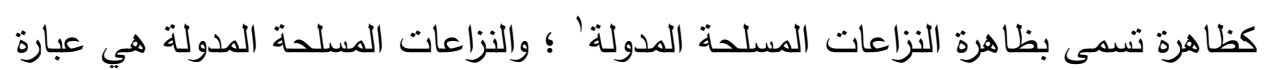

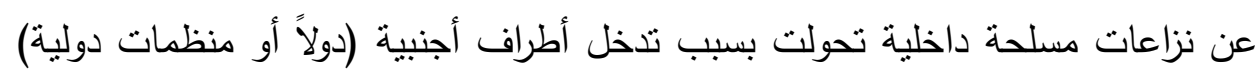
إلى نزاعات مسلحة ددولة. وتتتنل المشكلة الرئيسية بشأن النزاعات المسلحة المدولة في

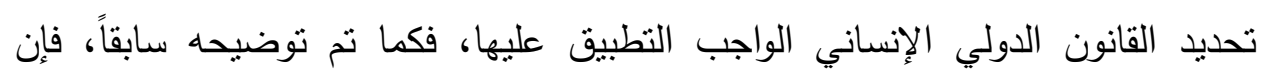
القانون الدولي الإنساني لا يطبق كوحدة واحدة متكاملة على كافة النزاعات الدسلحة، بل الإنل يتم تجزئته وتقسيمه عند التطبيق بحيث تطبق قواعد النزاعات المسلحة الدولية على الإلى

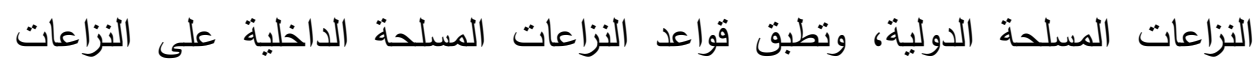

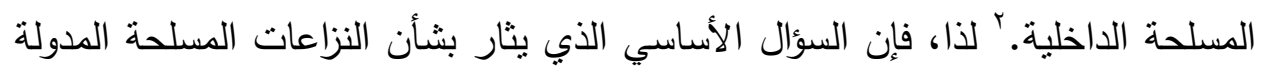

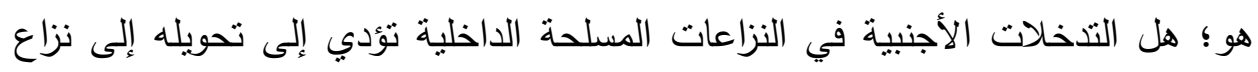

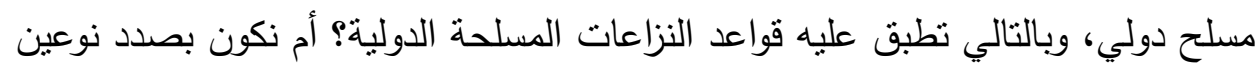

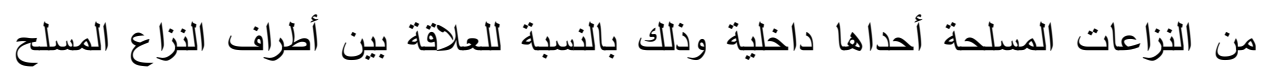

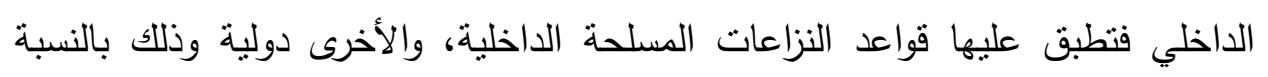

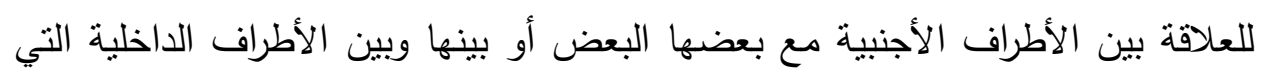

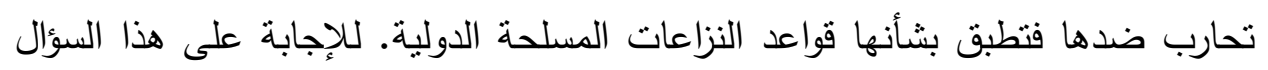

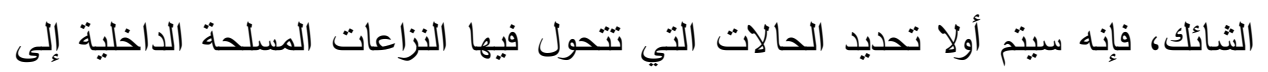
مدولة، ثم سيتم ثانياً تحديد الأثر القانوني المترتب على التى ندويل النزاع المسلح الداخلي.

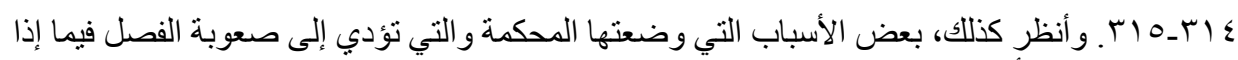

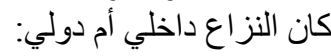

The prosecutor v. Tadic ICTY Appeals Chamber Decision on Jurisdiction, 2 October 1995 (97).

' ومن هذه الحروب، حرب الكونتر ا في نيكار اجوا، الحرب اللبنانية، حرب يو غو سلافيا السابقة، التدخل

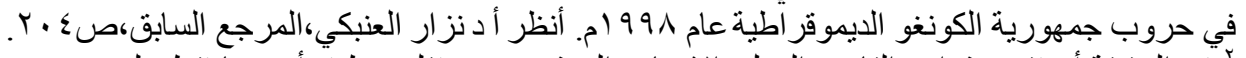

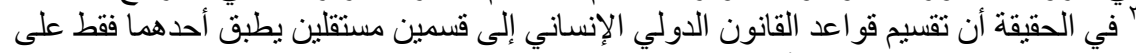

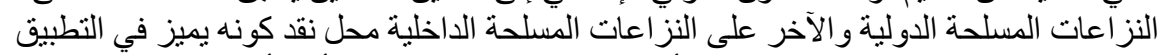

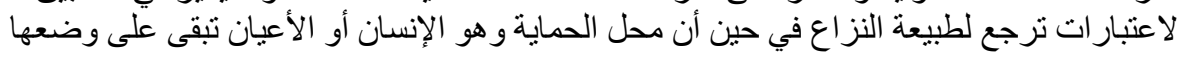

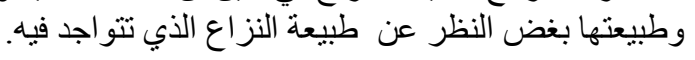




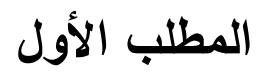

\section{الحالات التي تتحول فيها النزاعات المسلحة الداخلية إلى نزاعات}

مدولة

بينت المحكمة الجنائية الدولية الخاصة بيوغوسلافيا السابقة بأنه يمكن أن يحدث التدويل في حالتين، الأولى عندما يشارك أحد أطراف النزاع المسلح الداخلي في القتال تحقيقاً لمصلحة دولة أجنبية، والثانية عندما تتدخل دولة أجنبية عسكرياً في النزاع المسلح

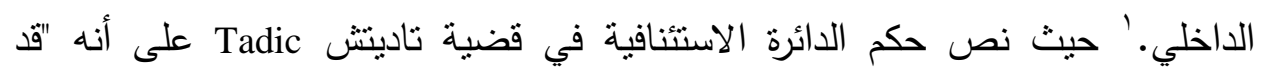

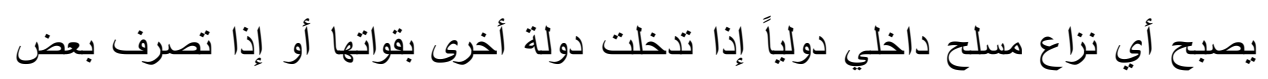
المشاركون في النزاع نيابة عن دولة أخرى".

\section{الفرع الأول}

\section{المشاركة في الأعمال المسلحة الداخلية لتحقيق مصلحة دولة أجنبية}

يثار التساؤل حول ما هو المعيار الفاصل، أو اختبار القياس المعتدد للقول بأن مشاركة طرف ما في القتال في نزاع مسلح داخلي هي مشاركة يهدف منها تحقيق

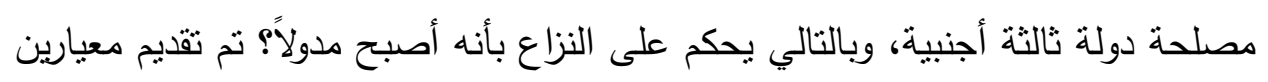
أو اختبارين قياس مختلفين من قبل المحاكم الدولية، الأول ينسم بالصرامة هو معيار السيطرة الفعالة effective control الذي تم تبنيه من قبل محكمة العدل الدولية في قضية

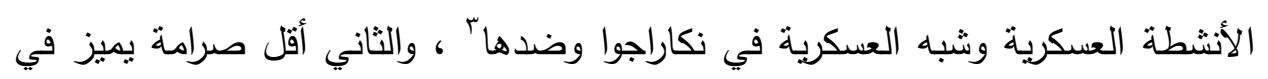

' كما يمكن أن ينم التدويل بسبب نثأة دولة أو دول خلال فترة النزاع المسلح الداخلي، أنظر: The prosecutor v. Tadic ICTY Appeals Chamber judgment, 15 July 1999 (88)(97).

' أنظر ملخص حكم الدائرة الاستئنافية الصادر في 10 يوليو 1999 في قضية المدعي العام ضد دوسكو

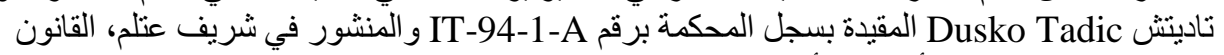

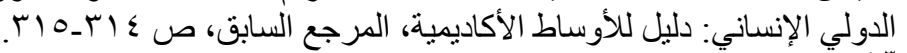

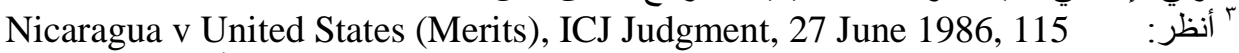

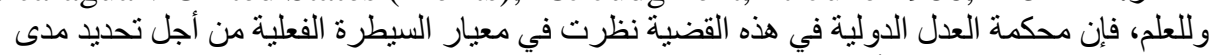

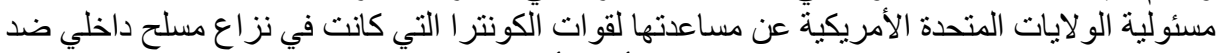

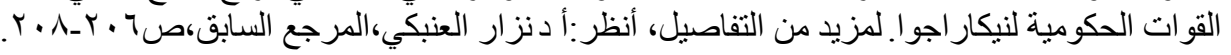


مدى سيطرة الدولة الأجنبية المطلوبة على الكيانات أو المجموعات المتمردة تبعاً لطبيعة هذه المجموعات والكيانات، فإذا كانت جماعات مسلحة منظمة كالجماعات شبه العسكرية فالسبطرة المطلوبة تكون بدرجة أقل وهي السبطرة العامة أو الكلية ”overall control“"، أما إذا كانت تللك الجماعات مكونة من مجرد أفراد أو من جماعات مسلحة غير منظمة فإن السيطرة المطلوبة هي السيطرة الفعالة الصارمة effective control ، وهذا ما تم تنبنيه من قبل دائرة الاستئناف للمحكمة الجنائية الدولية الخاصة بيوغسلافيا السابقة في قضية تاديتش Tadic، وكذلك تم تبنيه لاحقاً من قبل مؤسسات ومحاكم دولية كثيرة مثل لجنة

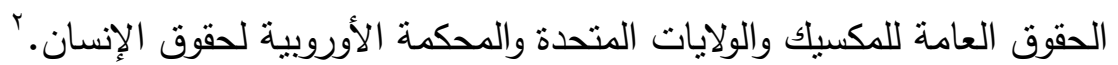

ويعتبر معيار السيطرة الفعالة effective control متحقق متى ما قامت الدولة الأجنبية بإصدار الأوامر والتعليمات للجماعات المسلحة (أو الأفراد حسب حكئ مكم دائرة الاستثناف في قضية تاديتش) لارتكاب أفعال معينة، حيث لا يكفي مجرد تقديم الدولة

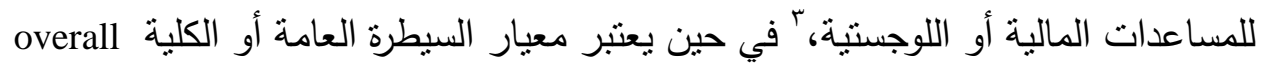
متحقق منى ما كانت الدولة الأجنبية تمارس سبطرة عامة على الجماعة المسلحة

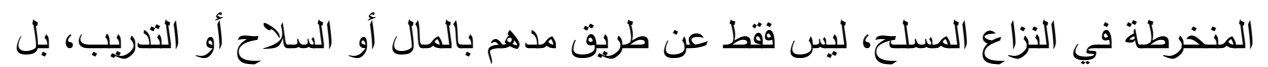
أيضاً عن طريق المشاركة والمساعدة في التخطيط للعمليات العسكرية والإثراف عليها، بيد أنه، وعلى عكس اختبار السيطرة الفعلية، لا يشترط إصدار أوامر أو تعليمات محددة تتعلق بأعمال عسكرية بعينها.

The prosecutor v.Tadic ICTY Appeals Chamber judgment,15 July 1999,(100, 120)

r أنظر ملخص حكم الدائرة الاستئنافية الصادر في 10 يوليو 1999 في قضية المدعي العام ضد دوسكو

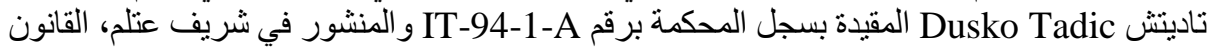

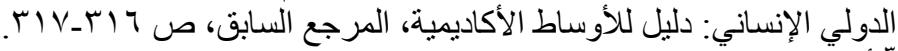
(أنظر

Nicaragua v United States (Merits), ICJ Judgment, 27 June 1986, 115. The prosecutor v. Tadic ICTY Appeals Chamber judgment, 15 July 1999, (100).

The prosecutor v. Tadic ICTY Appeals Chamber judgment, 15 July 1999, (131). 


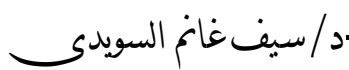

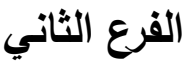

\section{التذخل العكري الأجنبي في النزاع المسلح الداخلي}

يتخذ التنخل العكري الأجنبي في النزاع المسلح الداخلي عدة صور هي؛ (1)

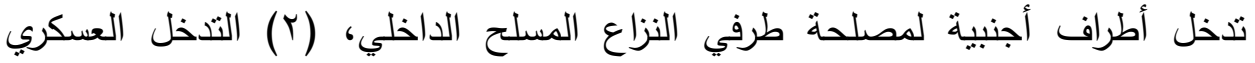

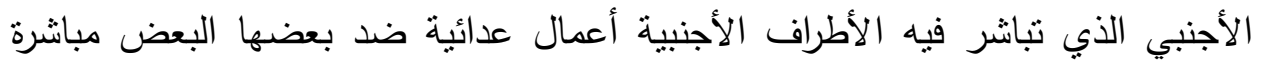

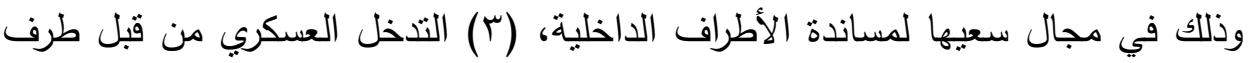

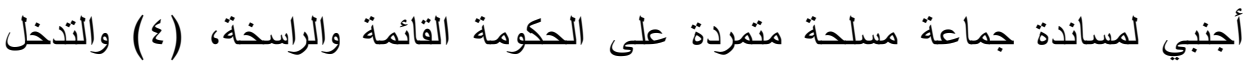
العسكري من قبل طرف أجنبي لمساندة الحكومة القائمة والراسخة ضد جماعة مسلحة متمردة عليها. والسؤال الذي يثور بثأن هذه التنخلات ما هو الددى المطلوب من التخخل

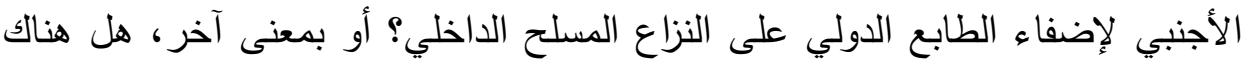

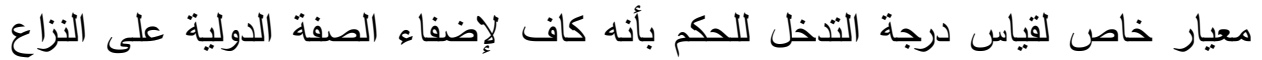

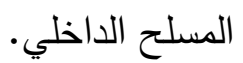

لا يوجد معيار موضوعي متفق عليه بثأن تحديد المدى المطلوب من التخخل لإضفاء الطابع الدولي على النزاع المسلح الداخلي، لكن المحكمة الجنائية الدولية

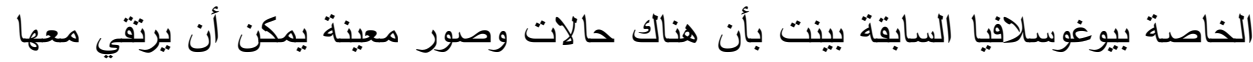

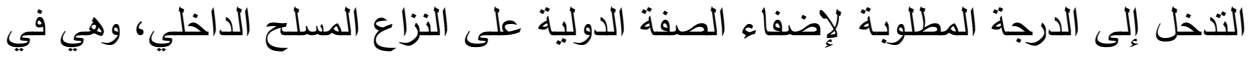
سبيل تحديد نلك الحالات اعتمدت على دراسة وتحليل الظروف الصصاحبة للنزاع بشكل التكل

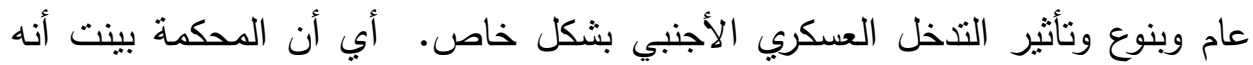

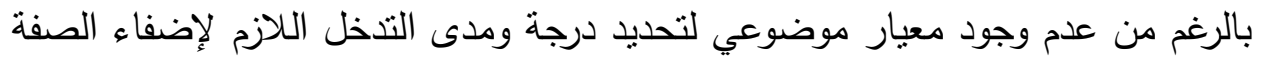

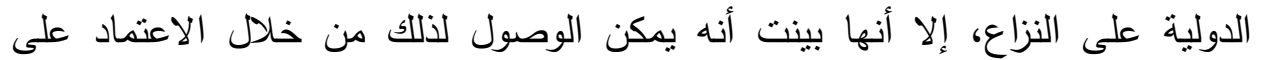
السلطة التقديرية المبنية على ظروف كل حالة على حدة. ومن الصور التي أقرتها الدحكمة باعتبارها تدخلات وصلت للارجة المطلوبة لغرض تدويل النزاع هي التخخل

أنظر كذلك أنظر ملخص حكم الدائرة الاستئنافية الصادر في 10 يوليو 1999 الئي في قضية المدعي العام

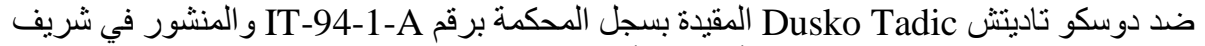

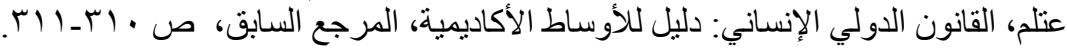


العسكري المباشر والمشاركة في العمليات العدائية ضد أحد طرفي القتال الداخلي، وكذلك التذخل العسكري غير المباشر الذي يؤثز على سير العمليات العدائية في منطقة النزاع كتمركز القوات الأجنبية في منطقة خارج النزاع ذات أهمية استراتيجية بالنسبة للنزاع، كتلك التي تقع بين مواقع طرفي النزاع، تساعد على تحقيق أفضلية لأحد طرفي النزاع.

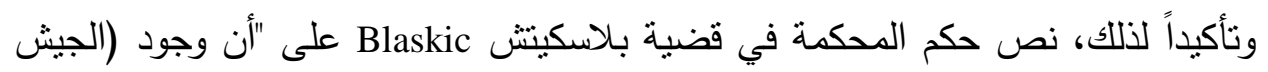

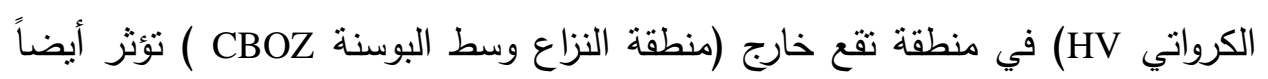

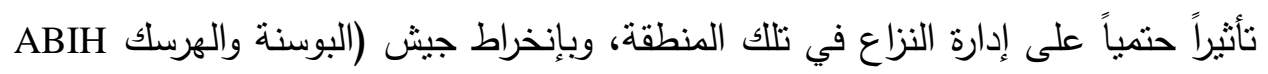

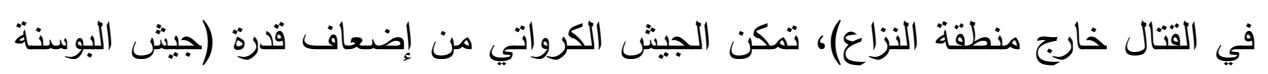

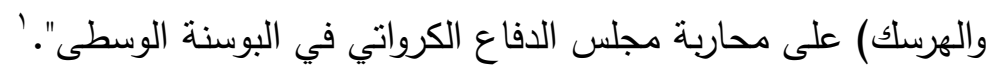

إن الاعتماد على السلطة التقديرية لأجل تحديد نوافر المدى المطلوب في التذخل

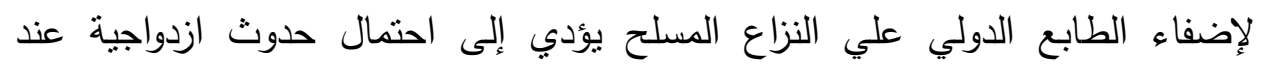
التطبيق حيث يمكن تكييف تدخلات عسكرية معينة (بالرغم من شدتها وقوتها ومشاركتها المباشرة) على أنها غير مستوفاة للمدى المطلوب، في حين يمكن أن تكيف تدخلات أقل

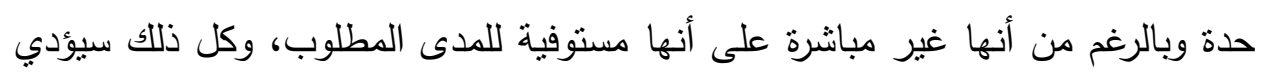
إلى تجاهل أساس التمييز بين النزاعات المسلحة المدولة وبين النزاعات المسلحة الداخلية

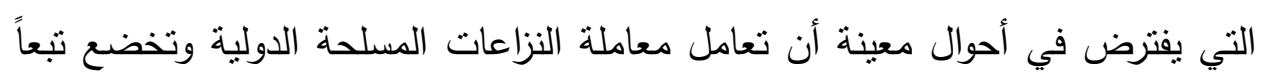
لذلك لأحكام قانون النزاعات المسلحة الدولية وليس الداخلية.

The Prosecutor v. Blaskie, ICTY, IT-95-14, Judgement, 3March 2000, para 9 . 


\section{المطلب الثاني}

\section{الأثر القانوني المترتب على تدويل النزاع المسلح الداخلي}

وفقاً لما تمت الإشارة إليه أعلاه، فإن أحكام القانون الدولي الإنساني لا نطبق بشكل

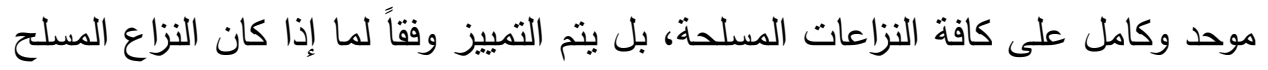

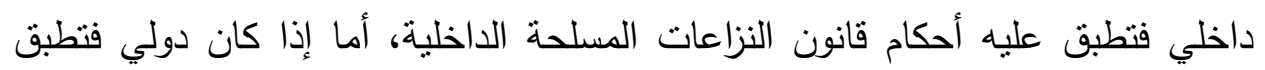
عليه أحكام قانون النزاعات المسلحة الدولية. ومن ناحية أخري، فإن النزاعات المسلحة الماتهة

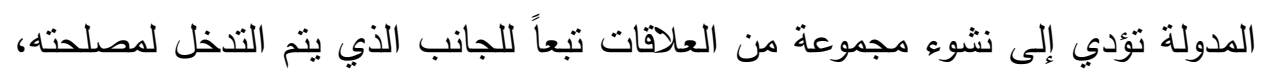

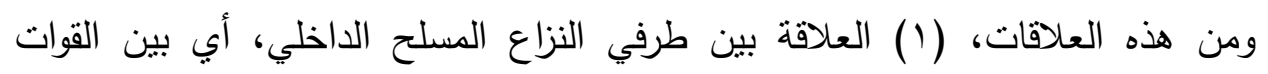

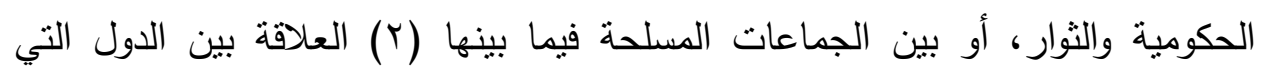
تتدخل لمصحة طرفي النزاع المسلح الداخلي، (ب) العلاقة بين الحكومة القائمة والدولة

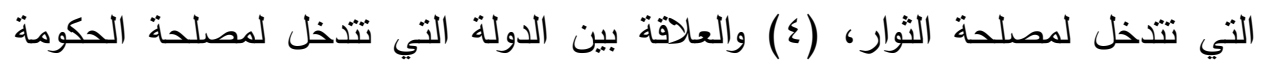

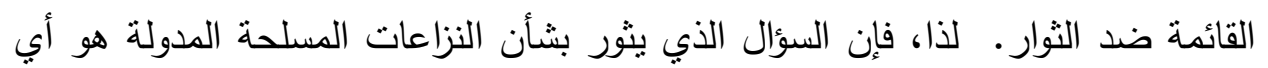

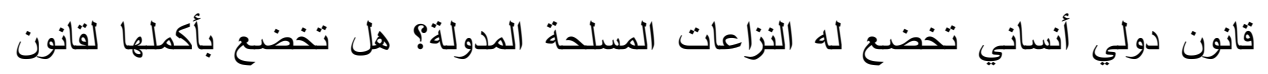

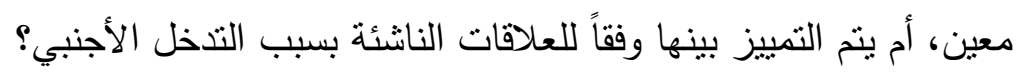

اعتمدت المحكمة الجنائية الدولية الخاصة بيوغوسلافيا السابقة المنهج المختلط'

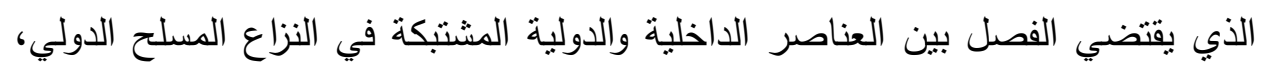
والذي ينترتب عليه اعتبار العلاقات فيما بين الأطراف الدولية خاضعة لأحكام قانون

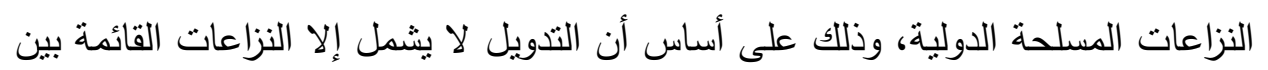

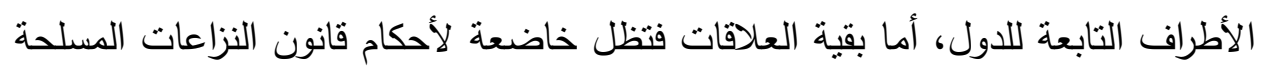
الداخلية.`ُوطبقاً لذلك، فإن العلاقة فيما بين طرفي النزاع المسلح الداخلي، وكذلك العلاقة

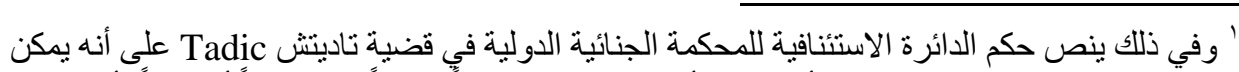

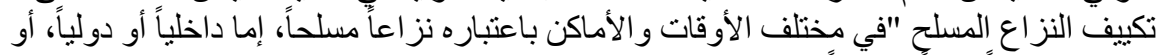
باعتباره نز اعاً دولياً مختلطاً".

The prosecutor v.Tadic ICTY Appeals Chamber judgment,15 July 1999, para73. 
بين الدولة التي تثنخل لمصلحة الحكومة القائمة ضد الثوار تكون خاضعة لقانون النزاعات المسلحة الداخلية، أما العلاقة بين الدول التي تتذخل لمصلحة الثوار، وكذلك العلاقة بين الحكومة القائمة والدولة التي تتدخل لمصلحة الثوار، فتكون خاضعة لقانون النزاعات المسلحة الداخلية.'

وقد واجه المنهج المخنلط ولا يزال يواجه معارضة من قبل الفقه ومن بعض القضاة

الدوليين كما تفصح عنه آرائهم المخالفة الإنفراديةّ وكذللك من قبل اللجنة الدولية للصليب الأحمر وذللك من خلال المشاريع والاقتراحات التي تقدمها في إطار جهودها الرامية لتطوير وإنماء القانون الدولي الإنساني وتحسين تطبيقه على مجمل النزاعات المسلحة. وينادي هذا الاتجاه بتطبيق المنهج الثامل الذي يقضي بتطبيق القانون الدولي الإنساني بأكمله كوحدة واحدة وفي آن واحد على النزاعات المسلحة المدولة، كحالة النزاعات المسلحة في إقليم يوغوسلافيا السابقة. لكن هذا المنهج الثامل لن يصبح راسخاً ومعتمداً في الوقت القريب - خصوصاً مع عدم وجود بوادر باللجوء إلبه من قبل القضاء الدولي - إلا إذا تم تبنيه من قبل المجتمع الدولي سواء في الاتفاقات الدولية أو من خلال التطبيق الدولي.

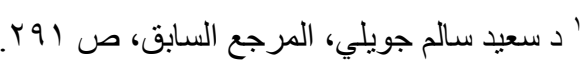

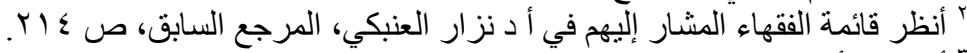

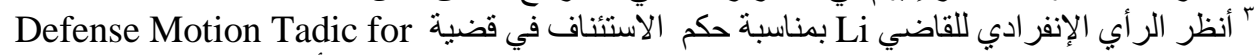
رودئز 17-18 رودريجز Rodrigues في حكم دائرة المحاكمة في قضية ICTY, prosecutor v.Alksovski, case.No.IT-95-14/1, judgment,25 June 1999 para 9, 22.

؛ أنظر تقرير اللجنة الدولية للصليب الأحمر المقدم إلى أعمال المؤتمر الدبلوماسي للخبر اء الحكوميين التحضيري بشأن تأكيد وتطوير القانون الدولي الإنساني (Geneve. 1972 Vol. 1, para.2.332. 


\section{المبحث الرابع}

\section{أوضاع تخرج من الاختصاص المادي للقانون الدولي الإنساني}

\section{الاضطرابات والتوترات الداخلية}

استبعد البروتوكول الثاني الإضافي لعام 9VV ام الإضطرابات والتوترات الداخلية

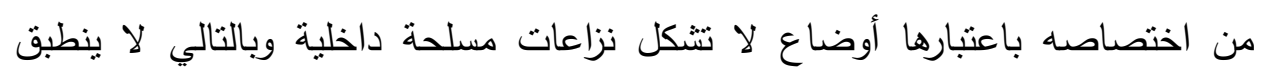

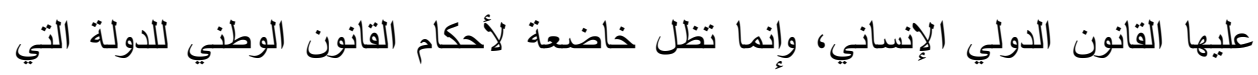

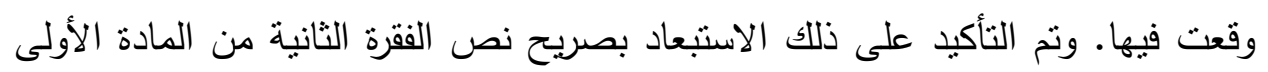

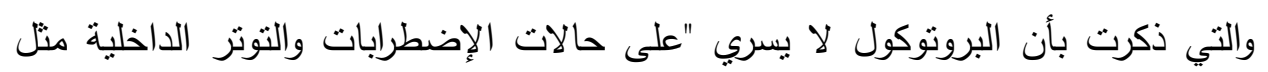

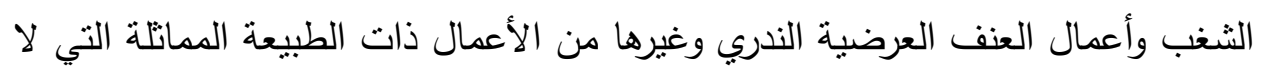

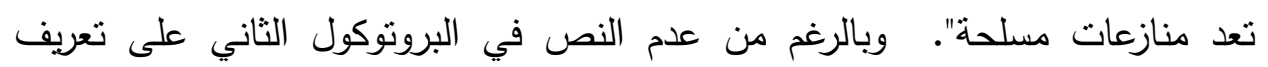

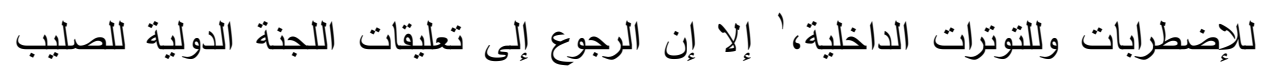

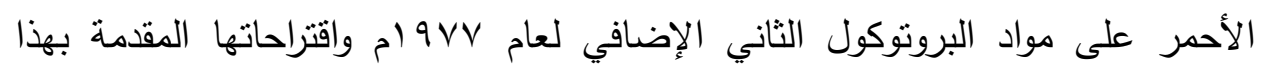

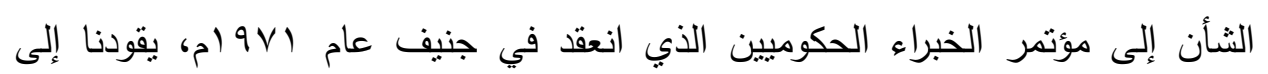

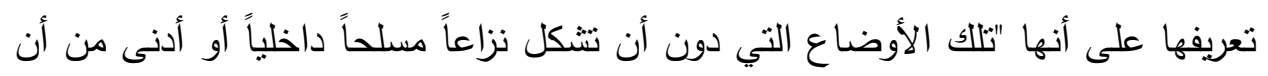

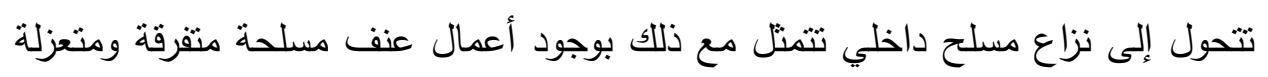

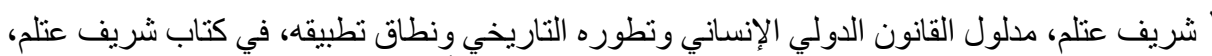

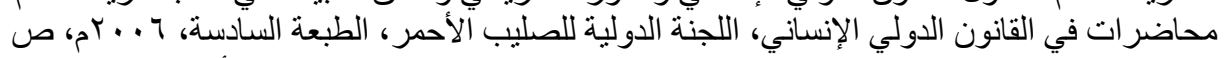

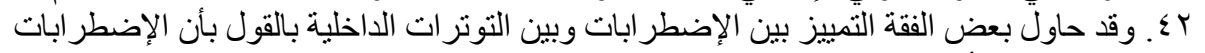

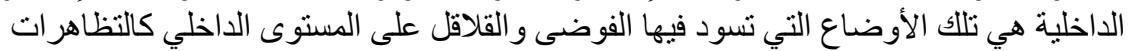

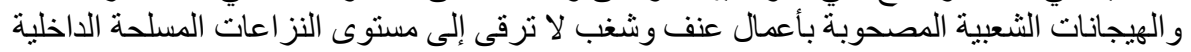

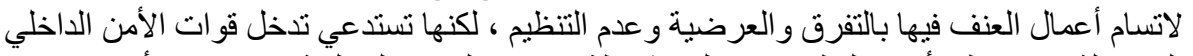

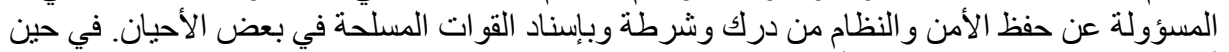

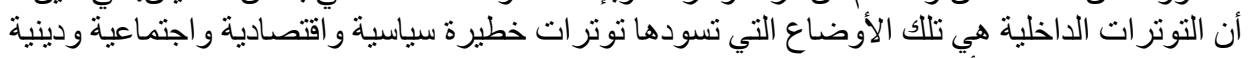

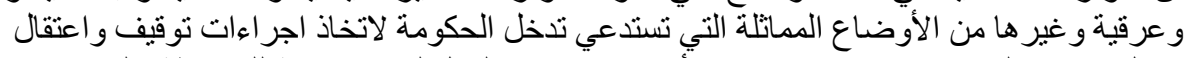

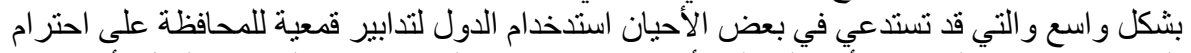

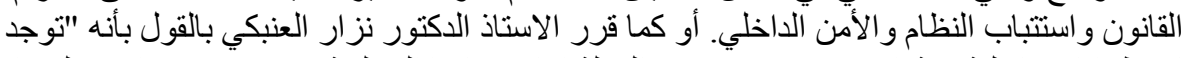

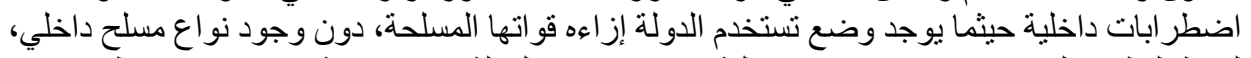

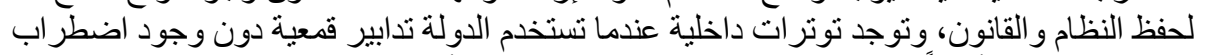

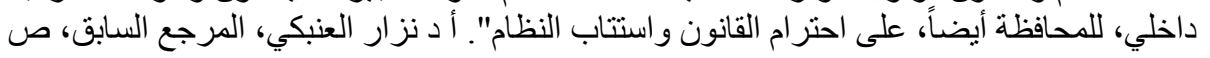


وعفوية وتفتقد إلى التظيم، فضلاً عن أنها غير منطاولة من حيث الزمان لكنها تستدعي مع ذلك تخخل القوات الثرطية والدركية المسؤولة عن حفظ النظام وسائر قوى الأمن الداخلي وحتى القوات المسلحة إن اقتضى الأمر تدخل هذه القوات بغية إعادة الأمن والنظام واحترام القانون إلى نصابها المعهود أو أنها تتميز على الأقل، كما في حالة الته التوترات الداخلية، بوجود توترات سياسية مختلفة تواجه بتدابير قسرية وقائية".' فهذه

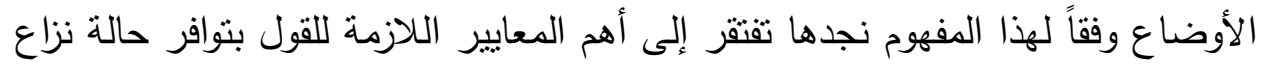

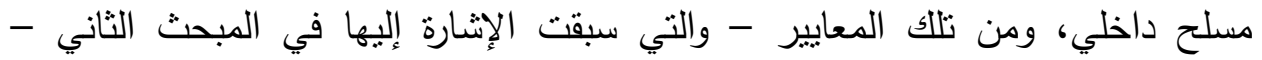
معيار درجة وكثافة العنف المسلح ومعيار التنظيم والقيادة اللازم توافرها للقوات المشتبكة مع الحكومة. وبناءً عليه، تعتبر هذه الأوضاع غير قادرة للرقي لاعتبارها نزاعات مسلحة داخلية، بل تظل مجرد أوضاع داخلية خاضعة لاختصاص القانون الوطني للدول. بعبارة

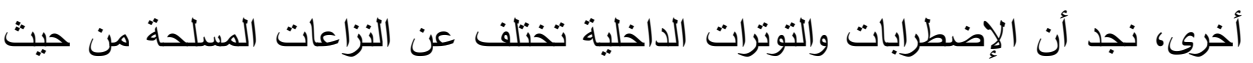
أن أعمال العنف المسلحة والمستخدمة بها نكون متفرقة ومنعزلة وعرضية وتفتقا إلى منى الإنى

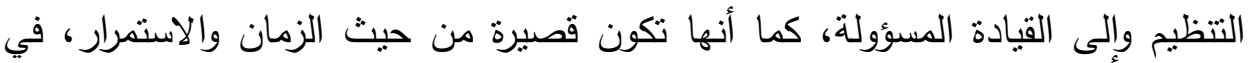
حين تتميز أعمال العنف المسلح في النزاعات المسلحة الداخلية بالثدة والتتظيم والتسيق هنيق

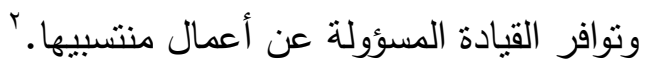
وتجدر الإثارة إلى أنه وبالرغم من عدم خضوع هذه الأوضاع لاختصاص القانون الدولي الإنساني وخضوعها كلية لاختصاص القانون الوطني للاول، إلا أنها نظل خاضعة للحد الأدنى من القواعد الإنسانية“ّ ولاختصاص القانون الدولي لحقوق الإنسان

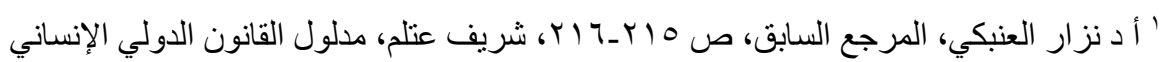

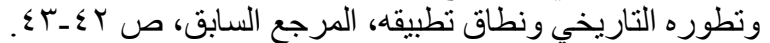

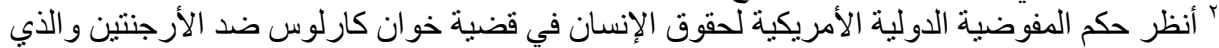
قضت فيه بأنه:

"An armed conflict must be contrasted with 'disturbances with no concerted intent' and 'isolated and sporadic acts of violence". Juan Carlos Abella v Argentina, Inter-American Commission on Human Rights Case No 11.137, Report No 55/97, 18 November 1997, 149.

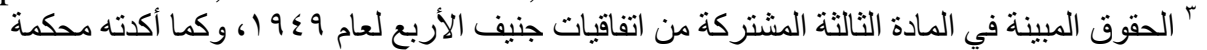

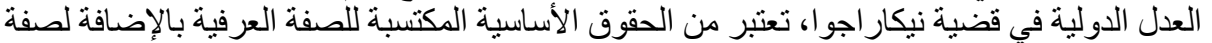

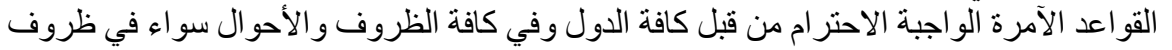


د د سيف غايم السويدى

مع جواز تقييد هذه الحقوق في الظروف الاستثنائية وحالات الطوارئ التي تهدد حياة الشعب'، منل الحق في تقييد حرية التتقل والتجوال في حالات الطوارئ لأجل فرض فئل

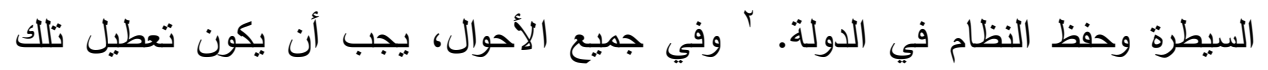
القوانين في تلك الظروف الاستثنائية بموجب اجراءات قانونية تتتهي بانتهاء تلكي

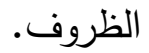

نز اعات مسلحة دولية أم داخلية أم حتى في ظروف حالات الطوارئ، لذا فإنها تشكل ((مقياساً للحد

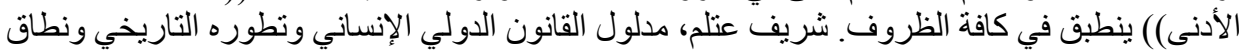

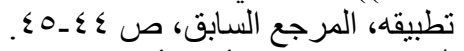

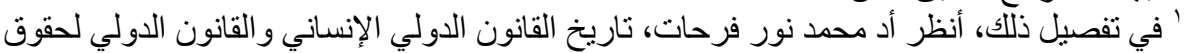

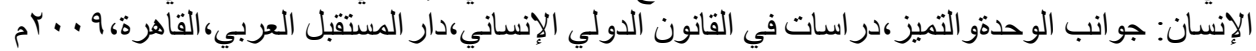

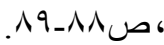

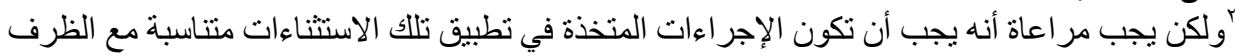

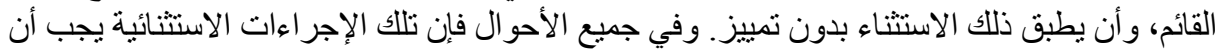

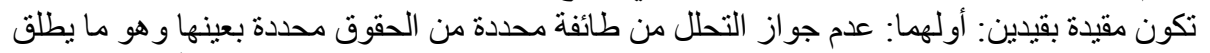

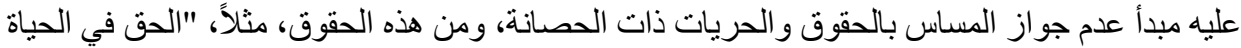

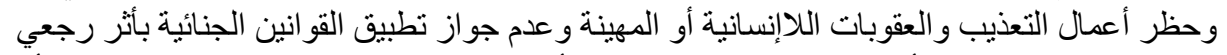

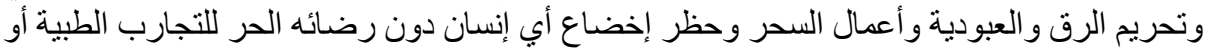

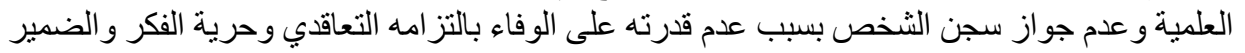

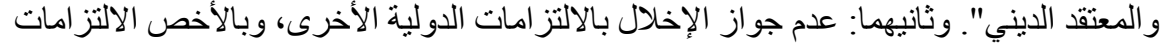

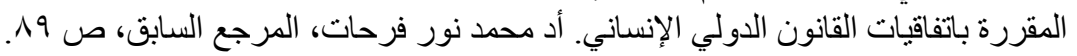




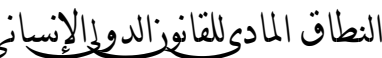

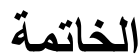

بان لنا أن أحكام القانون الدولي الإنساني تسري فقط على النزاعات المسلحة،

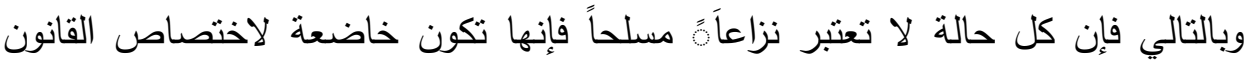
الوطني وخارجة عن اختصاص القانون الدولي الإنساني. لذا، فإن تحديد ماهية النزاعات

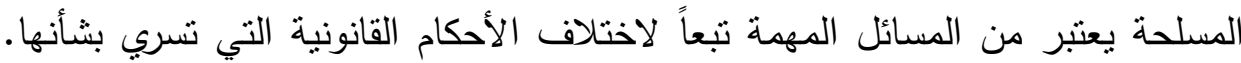
وتبين من خلال البحث بأن النزاعات المسلحة الخاضعة لاختصاص القانون الدولي الإنساني ليس ذات طبيعة واحة فمنها الدولية، والداخلية، والمختلطة. أما مجرد

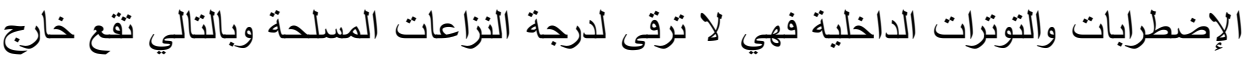
اختصاص القانون الدولي الإنساني.

وفيما يتعلق بالنوع الأول من النزاعات المسلحة وهي النزاعات المسلحة الدولية، فإن

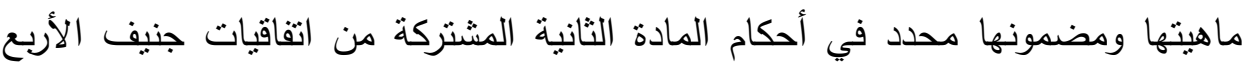

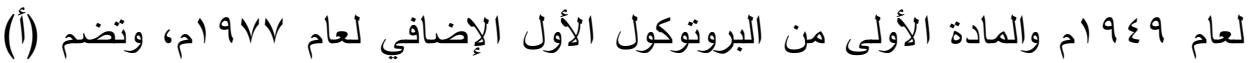

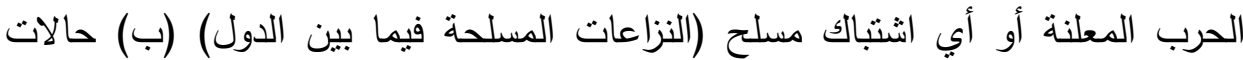
الاحتلال الكلي أو الجزئي حتى ولو لم تواجه بالمقاومة (ج) ومنازعات التحرر الوطني المسلحة أو ما يطلق عليها حروب التحرير الوطنية.

أما فيما يخص النزاعات المسلحة الداخلية، فإن مضمونها واسع ويشمل كل نزاع

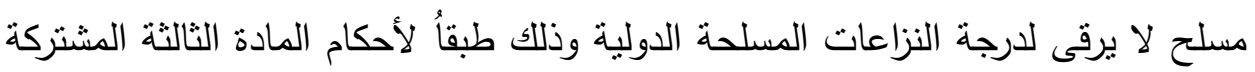

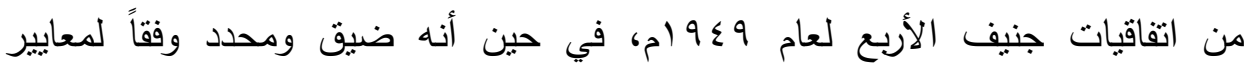

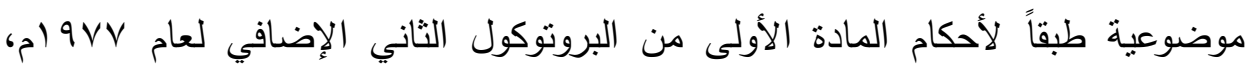
والذي يشنرط لاعتبار حالة معينة نزاع مسلح داخلي أن يقع ذلك النزاع المسلح داخل

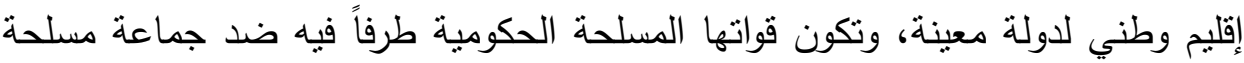

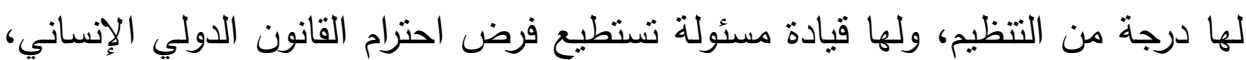

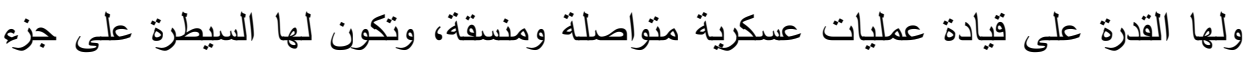

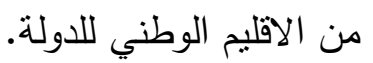


د د سيف غانم السويدى

أما النوع الثالث والأخير من النزاعات المسلحة الخاضعة لاختصاص القانون الدولي الإنساني فهي النزاعات المسلحة المدولة الني لم تتم الإشارة إليها في اتفاقيات القانون الدولي الإنساني ولكن الواقع العملي والفقه كثف عن وجودها المؤكد. والنزاعات المسلحة المدولة هي تللك النزاعات التي تكون ذات طابع دولي وداخلي في آن واحد، أو هي عبارة عن نزاعات مسلحة داخلية تحولت بسبب تدخل أطراف أجنبية (دولاً أو منظمات دولية) إلى نزاعات مسلحة مدولة. والتدويل يحدث إما بسبب مشاركة أحد أطراف النزاع المسلح الداخلي في القتال تحقيقاً لمصلحة دولة أجنبية، أو بسبب تدخل دولة أجنبية عسكرياً في

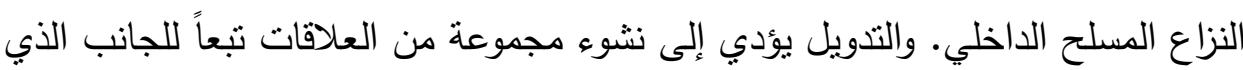
يتم التخخل لمصلحته، وهذه العلاقات هي (1) العلاقة بين طرفي النزاع المسلح الداخلي،

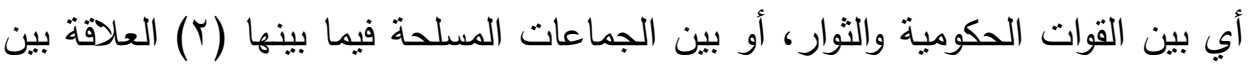
الدول التي تتدخل لمصحة طرفي النزاع المسلح الداخلي، (r) العلاقة بين الحكومة القائمة والدولة التي تتدخل لمصلحة التثار ، (ع) والعلاقة بين الدولة التي تتدخل لمصلحة الحكومة القائمة ضد الثوار. ويختلف القانون الذي يطبق بشأن هذه العلاقات تبعاً

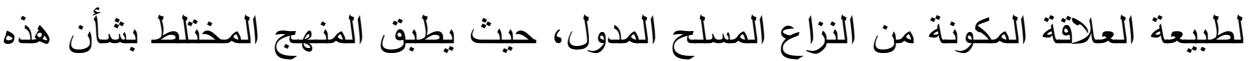

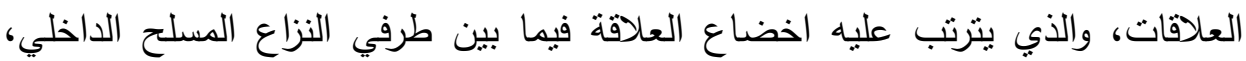
وكذللك العلاقة بين الدولة التي تتدخل لمصلحة الحكومة القائمة ضد الثوار لقانون النزاعات المسلحة الداخلية، أما العلاقة بين الدول التي تتلخل لمصلحة الثوار، وكذلك للك العلاقة بين الحكومة القائمة والدولة التي تتكخل لمصلحة الثوار، فتكون خاضعة لقانون النزاعات المسلحة الداخلية.

إن تجزئة القانون الدولي الإنساني إلى قسمين أحدهما خاص بالنزاعات المسلحة الدولية والآخر خاص بالنزاعات المسلحة الداخلية، لا يعتبر متوافق مع الغرض الإلى الإنساني للقانون الدولي الإنساني، حيث يفترض تطبيق مجمل مضمون وقواعد القانون الدولي الإنساني على جميع صور النزاعات المسلحة وبصرف النظر عن أي معيار شكلي آخر

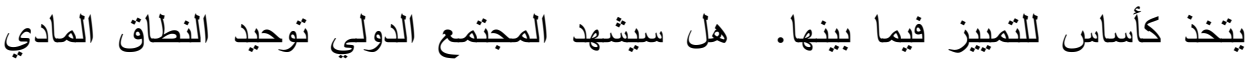
للقانون الدولي الإنساني؟ هذا ما نأمل أن يتم انجازه خلال الفترة القريبة القادمة معتمدين للين 
في ذلك على جهود المجتمع الدولي من جهة وجهود اللجنة الدولية للصليب الأحمر الراعي الرسمي للقانون الدولي الإنساني من جهة أخرى من جهي 


\section{قائمة المراجع}

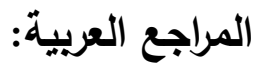

1- جان س بكتيه: النعليق على نصوص اتفاقيات جنيف الأوبع لعام 9 إم الصادر

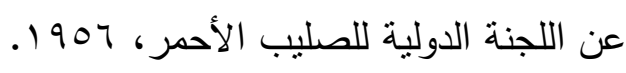
ז- جون ماري هنكرتس و لويز دوزوالد بك، القانون الدولي الإنساني العرفي، المجلد

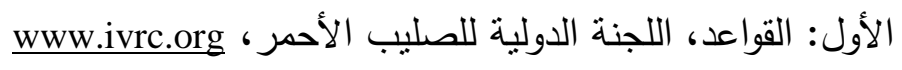

ז- د حازم محمد عتلم، قانون النزاعات المسلحة الدولية، الطبعة الأولى، مؤسسة دار

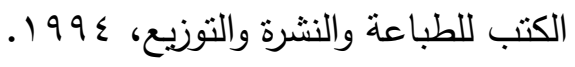
ع- د رانثد فهيد المري، الحماية القانونية المقررة لغير المشاركين في النزاعات المسلحة

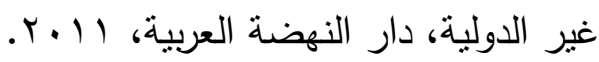
0- د سعيد سالم جويلي،الدذخل لدراسة القانون الدولي الإنساني، دار النهضة العربية، .r. r

צ- د سري صيام ، د شريف عتلم، القانون الدولي الإنساني وتطبيقاته في جمهورية

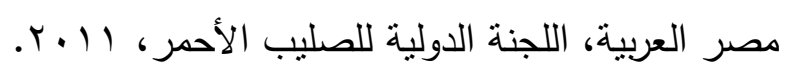

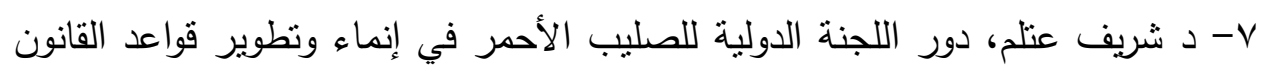
الدولي الإنساني، اللجنة الدولية للصليب الأحمر، ـ ـ r.

^- د شريف عنلم، القانون الدولي الإنساني: دليل للأوساط الأكاديمية، اللجنة الدولية

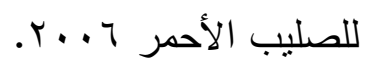
9 - شريف عتلم، مدلول القانون الدولي الإنساني وتطوره التاريخي ونطاق تطبيقه، في

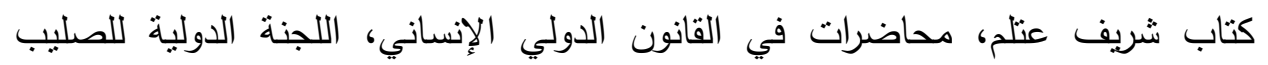

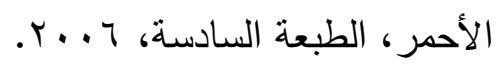


• 1- ماركو ساسولي، أنطوان بوفييه، سوزان كار، لينسي كامرون، توماس دي سان

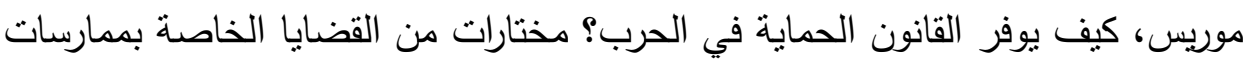

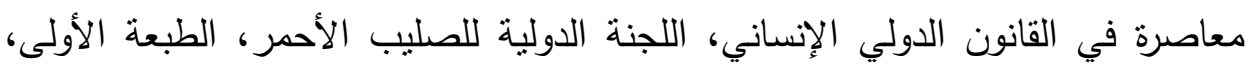

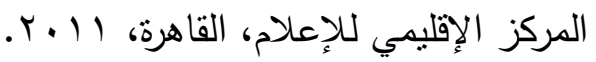

1 1 - د مصلح حسن أحدد عبدالعزيز ،مبادئ القانون الدولي الإنساني، دار الحامد،ب ا ـ ب.

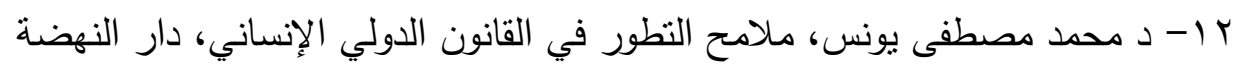

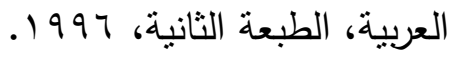

זا- د محدد نور فرحات، تاريخ القانون الدولي الإنساني والقانون الدولي لحقوق الإنسان: جوانب الوحدة والتميز، دراسات في القانون الدولي الإنساني، دار الدستقبل

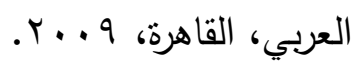

ع ا- د محمود السيد حسن داود، حماية ضحايا النزاعات المسلحة غير الدولية، في

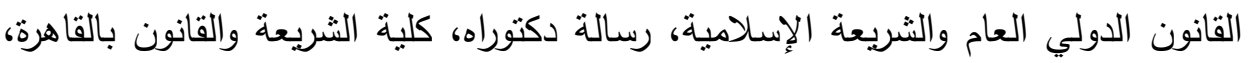

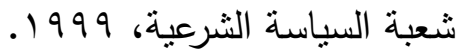

10- د نزار العنبكي، القانون الدولي الإنساني، دار وائل للنشر ، الطبعة الأولى · .ب٪.

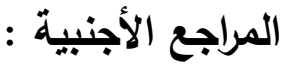

1- Jonathan Crowe \& Kylie Weston-Scheuber, Principles of International Humanitarian Law, Edward Elgar Publishing Limited, 2013.

2- Frits Kalshoven and Liesbeth Zegveld, Constraints on the Waging of War, Cambridge University Press, $4^{\text {th }}$ ed 2011. 
ـد/سيف غانم السويديـــ

\section{الفهرس}

orl

المقدمة:

ors

المبحث الأول : النزاعات المسلحة الدولية

oro

المطلب الأول.

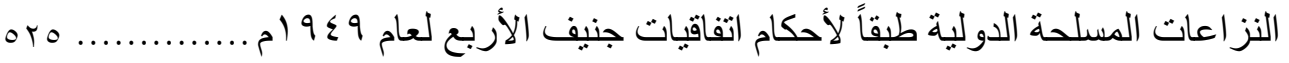

ors المطلب الثناني. - n

ors النز اعات المسلحة الدولية طبقاً لأحكام البروتوكول الإضافي الأول لعام qVV ام...

OrT المبحث الثانى : النزاعات المسلحة غير الدولية (الداخلية). ory

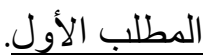

النزاعات المسلحة الداخلية في نطاق المادة الثالثة المشتركة من اتفاقيات جنيف الأربع orr

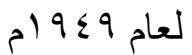

$0 \leqslant V$ المبحث الثالث : النزاعات المسلحة المدولة

$0 \leqslant 9$

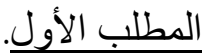

$0 \leqslant 9$ الحالات التي تتحول فيها النز اعات المسلحة الداخلية إلى نزاعات مدولة oor المطلب الثاني oor الأثر القانوني المترتب على تدويل النزاع المسلح الداخلي. المبحث الرابع : أوضاع تخرج من الاختصاص المادي للقانون الدولي الإنساني الاضطرابات

000 والتوترات الداخلية 001 الخاتمة.

071 قائمة المر اجع. Tr الفهرس 